\title{
Efficacy and Stability of Quantal GABA Release at a Hippocampal Interneuron-Principal Neuron Synapse
}

\author{
Udo Kraushaar and Peter Jonas \\ Physiologisches Institut der Universität Freiburg, D-79104 Freiburg, Germany
}

\begin{abstract}
We have examined factors that determine the strength and dynamics of GABAergic synapses between interneurons [dentate gyrus basket cells (BCs)] and principal neurons [dentate gyrus granule cells (GCs)] using paired recordings in rat hippocampal slices at $34^{\circ} \mathrm{C}$. Unitary IPSCs recorded from BC-GC pairs in high intracellular $\mathrm{Cl}^{-}$concentration showed a fast rise and a biexponential decay, with mean time constants of 2 and $9 \mathrm{msec}$. The mean quantal conductance change, determined directly at reduced extracellular $\mathrm{Ca}^{2+} / \mathrm{Mg}^{2+}$ concentration ratios, was 1.7 nS. Quantal release at the BC-GC synapse occurred with short delay and was highly synchronized. Analysis of IPSC peak amplitudes and numbers of failures by multiple probability compound binomial analysis indicated that synaptic transmission at the BC-GC synapse involves three to seven release sites, each of which releases transmitter with high probability $(\sim 0.5$ in $2 \mathrm{~mm}$ $\left.\mathrm{Ca}^{2+} / 1 \mathrm{mM} \mathrm{Mg}^{2+}\right)$. Unitary BC-GC IPSCs showed paired-pulse depression (PPD); maximal depression, measured for $10 \mathrm{msec}$
\end{abstract}

intervals, was $37 \%$, and recovery from depression occurred with a time constant of $2 \mathrm{sec}$. Paired-pulse depression was mainly presynaptic in origin but appeared to be independent of previous release. Synaptic transmission at the BC-GC synapse showed frequency-dependent depression, with half-maximal decrease at $5 \mathrm{~Hz}$ after a series of 1000 presynaptic action potentials. The relative stability of transmission at the BC-GC synapse is consistent with a model in which an activity-dependent gating mechanism reduces release probability and thereby prevents depletion of the releasable pool of synaptic vesicles. Thus several mechanisms converge on the generation of powerful and sustained transmission at interneuron-principal neuron synapses in hippocampal circuits.

Key words: GABAergic interneurons; basket cells; dentate gyrus; unitary IPSCs; paired-pulse depression; release probability; functional release sites; vesicular pools; paired recording; multiple probability compound binomial analysis
GABAergic interneurons are the main presynaptic source of inhibitory synaptic transmission in the mammalian CNS (for review, see Freund and Buzsáki, 1996). Although interneurons numerically represent only $\sim 10 \%$ of the neuronal population, they control the activity of the entire neuronal network. In the hippocampus, several interneuron types have been identified that form synapses on different domains of their postsynaptic target cells (Han et al., 1993; Freund and Buzsáki, 1996). Interneurons that innervate the perisomatic domain of principal neurons, referred to as basket cells, mediate a particularly powerful form of inhibition. Activation of a single basket-type interneuron can suppress repetitive discharge and delay spike initiation in principal neurons (Miles et al., 1996). Furthermore, activation of a single interneuron can entrain spiking of target neurons and synchronize the activity of large neuronal ensembles (Cobb et al., 1995). The impact of basket cell-mediated inhibition may be explained by the anatomical location of synaptic contacts in the perisomatic region of their postsynaptic target cells. Alternatively, the efficiency could be caused by specific functional properties of basket cell output synapses, such as the number of functional release sites (Edwards et al., 1990; Tamás et al., 1997), the number of GABA molecules released from a single vesicle (Frerking et al., 1995), the number of postsynaptic $\mathrm{GABA}_{\mathrm{A}}$ receptors (Nusser et al., 1997, 1998), and the receptor occupancy after release (Edwards et al., 1990; Frerking et al., 1995).

Unlike principal neurons, basket-type interneurons are able to generate action potentials with high frequency during sustained

\footnotetext{
Received Feb. 17, 2000; revised April 24, 2000; accepted April 29, 2000.

This work was supported by grants from the Deutsche Forschungsgemeinschaft (SFB 505/C5) and the Human Frontiers Science Program Organization (RG0017/ 1998-B) to P.J. Novartis generously provided CGP55845A. We thank Drs. J. Bischofberger, F. A. Edwards, J. R. P. Geiger, M. V. Jones, M. Martina, and A. Roth for critically reading this manuscript. We also thank A. Blomenkamp for technical assistance.

Correspondence should be addressed to Dr. P. Jonas, Physiologisches Institut Universität Freiburg, Hermann-Herder-Strasse 7, D-79104 Freiburg, Germany. Email: jonasp@uni-freiburg.de.

Copyright (C) 2000 Society for Neuroscience $0270-6474 / 00 / 205594-14 \$ 15.00 / 0$
}

current injection in vitro (Han et al., 1993; Martina et al., 1998) and in vivo (Penttonen et al., 1998; Csicsvari et al., 1999). This suggests the possibility that the dynamic properties of output synapses of interneurons are adapted to high-frequency activity. In the neocortex, GABA release from interneurons is more stable than glutamate release from principal cells during high-frequency stimulation (Galarreta and Hestrin, 1998; Varela et al., 1999); however, the mechanisms underlying this stability are unknown. Stability of inhibition during high-frequency stimulation could be generated by a larger readily releasable pool of synaptic vesicles in comparison with excitatory synapses (Stevens and Tsujimoto, 1995). Alternatively, stability of inhibition could be conferred by a reduction of release probability during repetitive stimulation (Betz, 1970; Wu and Borst, 1999) or activity-dependent replenishment of the releasable pool of synaptic vesicles (Kusano and Landau, 1975; Dittman and Regehr, 1998).

A rigorous analysis of the factors determining the strength and dynamics of GABAergic synapses requires the selective stimulation of identified presynaptic interneurons in the paired recording configuration (Miles and Poncer, 1996). We have therefore examined unitary IPSCs at the basket cell (BC)-granule cell (GC) synapse in the dentate gyrus of hippocampal brain slices. Our results indicate that transmission at the $\mathrm{BC}-\mathrm{GC}$ synapse is very efficient, mainly because of a large quantal size and a high release probability. An activity-dependent gating mechanism that reduces release probability may help to preserve the releasable pool of synaptic vesicles.

\section{MATERIALS AND METHODS}

Paired recording. Transverse hippocampal slices (300 $\mu \mathrm{m}$ thickness) were cut from brains of 18- to 25-d-old Wistar rats using a vibratome (DTK1000, Dosaka). Animals were killed by decapitation, in agreement with national and institutional guidelines. Patch pipettes were pulled from thick-walled borosilicate glass tubing $(2 \mathrm{~mm}$ outer diameter, $0.5 \mathrm{~mm}$ wall thickness); when filled with intracellular solution, the resistance was 3-5 $\mathrm{M} \Omega$ for presynaptic recordings and 2-4 $\mathrm{M} \Omega$ for postsynaptic recordings. Simultaneous recordings from synaptically connected BCs and GCs in the 

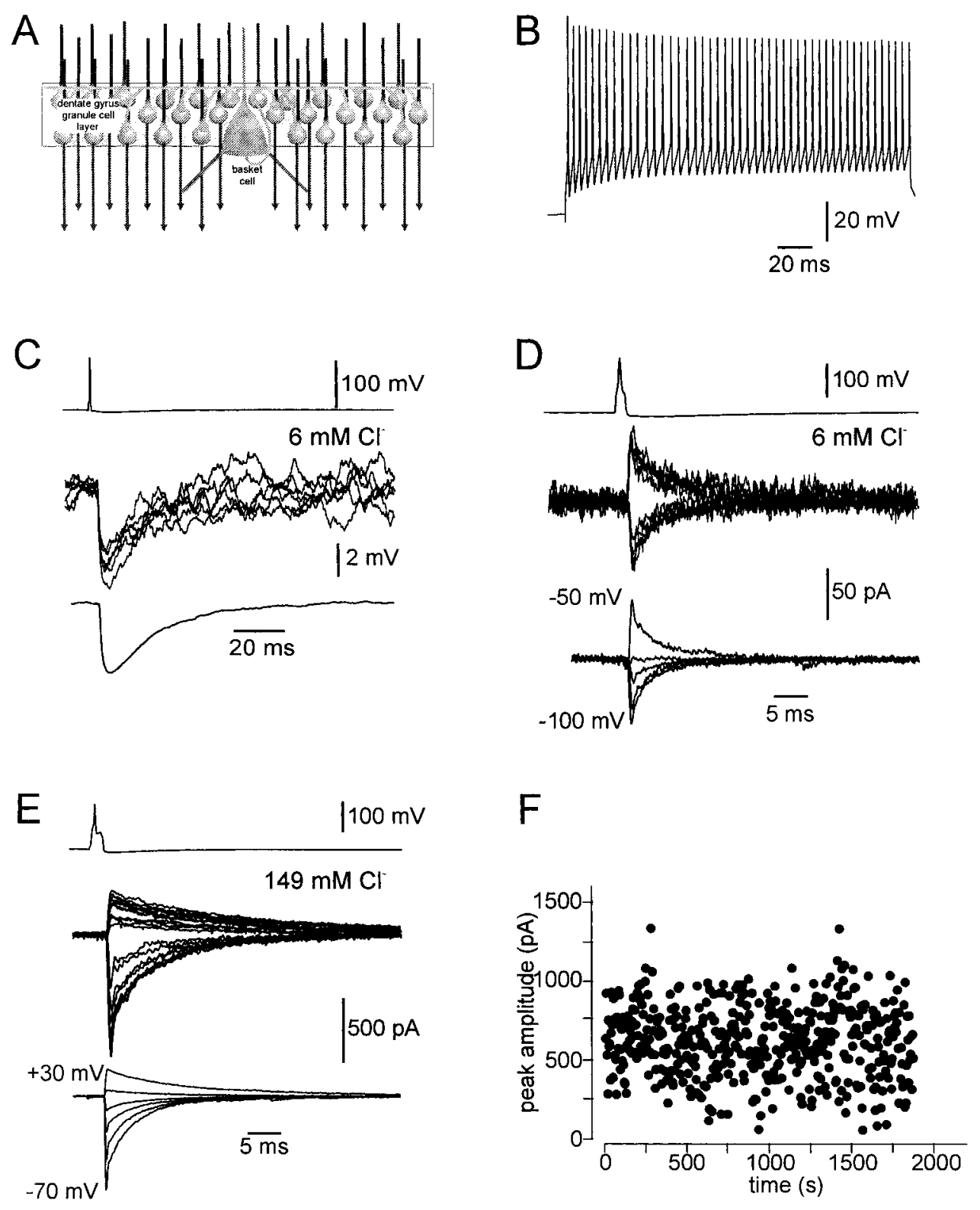

Figure 1. Unitary IPSPs and IPSCs at the BC-GC synapse in the paired recording configuration. $A$, Schematic illustration of the $\mathrm{BC}-\mathrm{GC}$ microcircuit in the dentate gyrus. $B$, High-frequency train of action potentials evoked in a putative $\mathrm{BC}$ by a current pulse (200 msec, $1.4 \mathrm{nA})$. $C$, Unitary IPSPs recorded from a BC-GC pair at -30 $\mathrm{mV}$ with $6 \mathrm{~mm}$ intracellular $\mathrm{Cl}^{-}$concentration. Single presynaptic action potential evoked by a depolarizing current pulse in the $\mathrm{BC}$ is shown on top, single IPSPs are shown superimposed in the center, and average IPSP is depicted at the bottom. $D$, Unitary IPSCs in a BC-GC pair with $6 \mathrm{~mm}$ intracellular $\mathrm{Cl}^{-}$concentration. Single presynaptic action potential is shown on top, single IPSCs at -100 and $-50 \mathrm{mV}$ are shown superimposed in the center, and average IPSCs at -100 to $-50 \mathrm{mV}(10 \mathrm{mV}$ increment) are depicted at the bottom. E, Unitary IPSCs in a BC-GC pair with 149 mM intracellular $\mathrm{Cl}^{-}$concentration. Single presynaptic action potential is shown on top, single IPSCs at -100 and $+30 \mathrm{mV}$ are shown superimposed in the center, and average IPSCs at -70 to $+30 \mathrm{mV}(20 \mathrm{mV}$ increment) are depicted at the bottom. F, Unitary IPSC peak amplitude plotted against recording time. Note that the amplitude was stationary (correlation coefficient $r=0.05, p>0.1)$. Averages are from $30-$ 100 single synaptic events. Data in $C-F$ are from different pairs. Pair shown in $F$ is pair $\# 1$ in Table 2. dentate gyrus were obtained under visual control using infrared differential interference contrast videomicroscopy (Edwards et al., 1989; Stuart et al., 1993; Koh et al., 1995). A tight-seal ( $>2$ G $\Omega$ ) whole-cell recording was first established in a putative BC. Selected cells had somata located at the granule cell layer-hilus border and generated $>200$ action potentials during $1 \mathrm{sec}$ depolarizing current pulses (1.4-2 nA). Subsequently, whole-cell recordings were made from GCs; their somata were typically located in the outer half of the granule cell layer within $100 \mu \mathrm{m}$ distance from the BC soma. Under ideal conditions, the probability of inhibitory synaptic coupling between the BC and the GC was up to $50 \%$. Based on the morphological appearance of presynaptic neurons, fast spiking on sustained current injection (Koh et al., 1995), and fast rise time of evoked IPSCs in postsynaptic granule cells (see Fig. $3 C$ ), we denote the presynaptic neurons as putative basket cells, although we cannot exclude the possibility that they were axo-axonic cells or hilar interneurons with axon coaligned with the commissural-associational pathway (HICAP cells) in some cases (Freund and Buzsáki, 1996). Pairs with initial resting potentials more positive than $-60 \mathrm{mV}$ and more positive than $-70 \mathrm{mV}$ (BC and GC, respectively) or pairs in which evoked IPSCs triggered unclamped action potentials in the $\mathrm{GC}$ were discarded. The recording temperature was $34 \pm 2^{\circ} \mathrm{C}$.

Two Axopatch 200A amplifiers (Axon Instruments) were used for current- and voltage-clamp recording. The presynaptic neuron was held in the current-clamp mode and stimulated at a frequency of $0.25 \mathrm{~Hz}$, unless specified differently. Action potentials were elicited by brief current pulses (duration $1 \mathrm{msec}$, amplitude 1.4-2.4 nA). The postsynaptic cell was held in either the current-clamp or voltage-clamp mode, using series resistance
$\left(R_{\mathrm{S}}\right)$ compensation (nominally $85-95 \%$, lag $\sim 100 \mu \mathrm{sec} ; R_{\mathrm{S}}$ before compensation 5-20 M $\Omega$ ). The constancy of the series resistance in the postsynaptic $\mathrm{GC}$ was assessed from the amplitude of the capacitive current in response to a $5 \mathrm{mV}$ pulse, and the compensation was readjusted during the experiment when necessary. Presynaptic action potentials and IPSPs or IPSCs were filtered at $5 \mathrm{kHz}$ using the four-pole low-pass Bessel filter of the amplifiers and digitized at $10 \mathrm{kHz}$ using a 1401plus laboratory interface (Cambridge Electronic Design) connected to a Pentium-PC. Commercial programs from Cambridge Electronic Design were used for stimulus generation and data acquisition.

Solutions. The physiological extracellular solution contained (in $\mathrm{mm}$ ): $125 \mathrm{NaCl}, 25 \mathrm{NaHCO}_{3}, 25$ glucose, $2.5 \mathrm{KCl}, 1.25 \mathrm{NaH}_{2} \mathrm{PO}_{4}, 2 \mathrm{CaCl}_{2}, 1$ $\mathrm{MgCl}_{2}$. In some experiments, the $\mathrm{Ca}^{2+}$ and $\mathrm{Mg}^{2+}$ concentrations were varied to alter the release probability. The intracellular solution contained (in mM): $145 \mathrm{KCl}, 0.1$ EGTA, $2 \mathrm{MgCl}_{2}, 2 \mathrm{Na}_{2} \mathrm{ATP}$, and $10 \mathrm{HEPES}(\mathrm{KCl}$ intracellular solution); the $\mathrm{pH}$ was adjusted to 7.2 with $\mathrm{KOH}$. In some experiments, a solution containing (in mM): $140 \mathrm{~K}$-methylsulfate, $2 \mathrm{KCl}, 10$ EGTA, $2 \mathrm{MgCl}_{2}, 2 \mathrm{Na}_{2} \mathrm{ATP}$, and 10 HEPES (K-methylsulfate intracellular solution, $\mathrm{pH}$ adjusted with $\mathrm{KOH}$; see Fig. $1 C, D$ ) or a solution with (in mM): $145 \mathrm{CsCl}, 0.1$ EGTA, $2 \mathrm{MgCl}_{2}, 2 \mathrm{Na}_{2} \mathrm{ATP}$, and $10 \mathrm{HEPES}$ (CsCl intracellular solution, $\mathrm{pH}$ adjusted with $\mathrm{CsOH}$; see Fig. $1 E$ ) was used for the postsynaptic GC. For perforated-patch recordings, the intracellular solution contained (in $\mathrm{mM}$ ): $78 \mathrm{KCl}$, $78 \mathrm{~K}$-gluconate, $0.1 \mathrm{EGTA}, 2 \mathrm{MgCl}_{2}, 2 \mathrm{Na}_{2} \mathrm{ATP}$, $10 \mathrm{HEPES}$, and $18 \mu \mathrm{g} / \mathrm{ml}$ gramicidin; for tip filling, the same solution without gramicidin was used. Bicuculline methiodide was from Sigma (stock solution prepared in distilled water), CGP55845A was from Novartis 
Figure 2. Amplitude and time course of the unitary postsynaptic conductance change at the $\mathrm{BC}-\mathrm{GC}$ synapse. Data are from a single pair. $A$, Presynaptic action potential (top), single unitary IPSCs ( 9 sweeps superimposed), average IPSC (from 60 sweeps), and sum of two exponentials fitted to the average IPSC (bottom, with individual components) are depicted. $B$, Latency, measured from the steepest point in the rising phase of the presynaptic action potential to the onset of the first IPSC in a trace. $C$, Rise time $(20-80 \%)$ of unitary IPSCs. $D$, Peak amplitude of unitary IPSCs. Thirty-one failures are not displayed. $E$, Decay time constants of unitary IPSCs: fast decay time constant $\tau_{1}$ (open bars); slow decay time constant $\tau_{2}$ (filled bars). $F$, Amplitude contribution of the fast component of decay $\left(A_{1}\right)$ obtained by biexponential fit. Extracellular $\mathrm{Ca}^{2+}$ and $\mathrm{Mg}^{2+}$ concentrations were 2 and $1 \mathrm{~mm}$, respectively. Holding potential was $-70 \mathrm{mV}$; intracellular $\mathrm{Cl}^{-}$concentration in the postsynaptic GC was $149 \mathrm{~mm}$. All data are from the same $\mathrm{BC}-\mathrm{GC}$ pair.
A
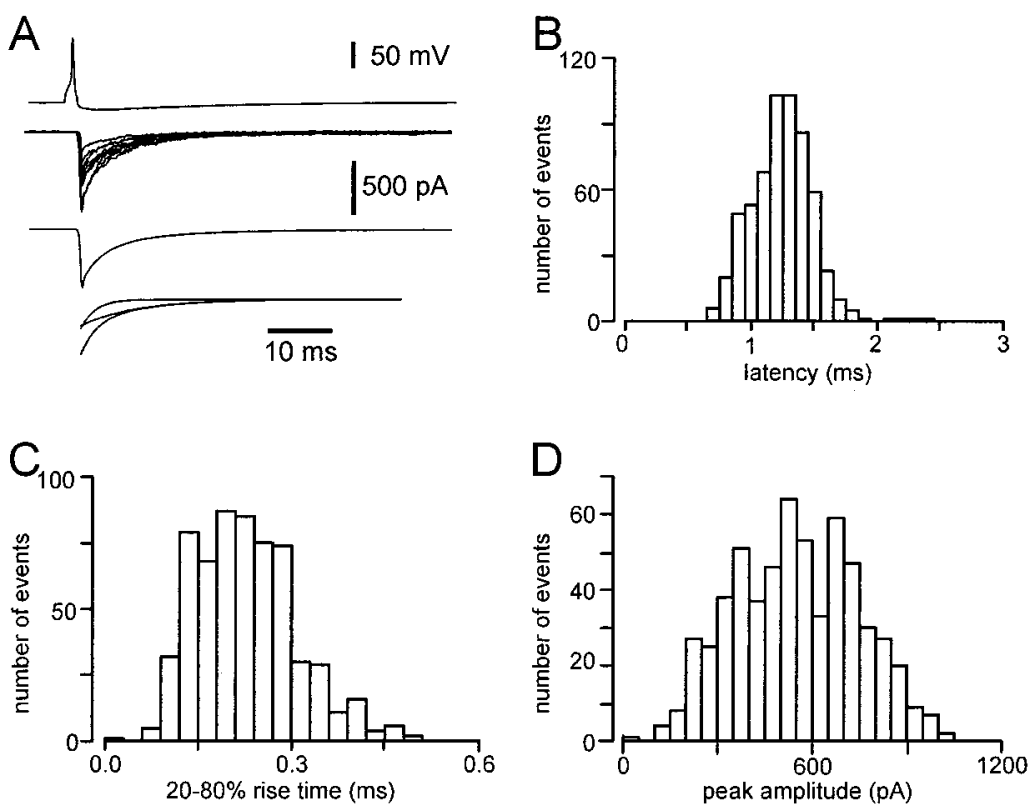

$\mathrm{E}$

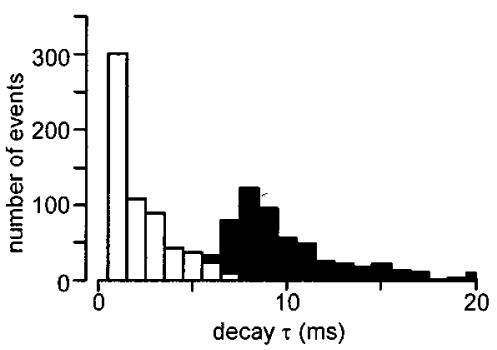

$F$

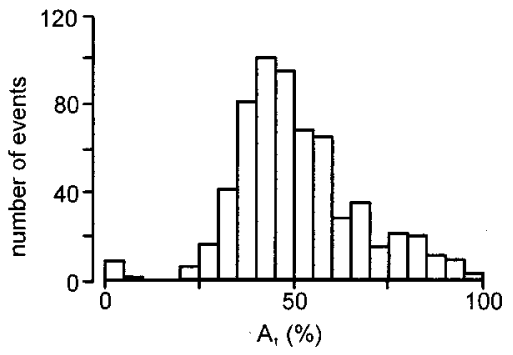

(stock solution in dimethylsulfoxide), K-methylsulfate was from ICN, and other chemicals were from Merck, Sigma, Riedel-de Haen, or Gerbu.

Data analysis. Evoked IPSPs and IPSCs were analyzed using programs written in Pascal (Borland, version 7.0). The rise time was determined as the time interval between the points corresponding to 20 and $80 \%$ of the peak amplitude, respectively. The peak current was determined as the maximum within a window of $2 \mathrm{msec}$ duration after the presynaptic action potential. The mean frequency of spontaneous events was $8.2 \pm 1.2 \mathrm{~Hz}$ (range: $0.9-17 \mathrm{~Hz} ; 18 \mathrm{GCs}$ ), indicating that contaminating spontaneous events with onsets in this window may occur in $1.6 \%$ of traces. The synaptic latency was determined as the time interval between the maximum of the first derivative of the presynaptic action potential and the onset of the first subsequent IPSC; the onset point was determined from the intersection of a line through the 20 and $80 \%$ points with the baseline. The decay phase of the IPSCs was fitted with the sum of two exponentials and a constant using a nonlinear least-squares fit algorithm; the best-fit value of the constant was close to zero in all cases. Amplitude ratios given refer to the time of the peak current. A trace was classified as a failure when the amplitude was less than three times the SD of the preceding baseline. Average IPSCs were obtained from single IPSCs aligned to the steepest point in the rise of the presynaptic action potential, unless specified differently.

The time course of quantal release was determined from the first latency histogram using the method of Barrett and Stevens (1972). To examine the validity of the approach, quantal IPSCs were aligned at their rising phase and averaged. The release probability distribution was reconvolved with the average quantal IPSCs by multiplying the respective discrete Fourier transforms with each other (Geiger et al., 1997). Coefficients of variation (CV, SD/mean) of unitary IPSC peak amplitudes were calculated from traces during stationary periods; the number of traces included was 20-50. $\mathrm{CV}$ values were not corrected for baseline noise (unless specified differently), because the influence of a correction was very small. To determine the locus of paired-pulse depression (PPD; see Fig. 7C) and its possible dependence on previous release (see Fig. 8), an interpulse interval of $\geq 100$ msec was used, which allowed the first IPSC to decay completely to baseline. Values are given as mean \pm SEM. Error bars in the Figures also indicate SEMs, unless specified differently. Membrane potentials reported in the text were not corrected for junction potentials. Significance of differences was assessed by two-tailed Student's $t$ test at the significance level $(p)$ indicated.

Multiple probability compound binomial analysis. To determine the number of functional release sites and the release probability, we used a hybrid approach [termed multiple probability compound binomial analysis (MP-CBA)] that combines elements of amplitude distribution fitting (Edwards et al., 1990; Jonas et al., 1993) and multiple probability variance analysis (Silver et al., 1998). Amplitude distributions and numbers of failures for two to four different $\mathrm{Ca}^{2+} / \mathrm{Mg}^{2+}$ concentration ratios obtained consecutively from the same pair were fitted with a compound binomial model of release (Redman, 1990). The number of traces recorded in each condition was $>100$. Data in each condition were tested for stability of series resistance and stationariness of peak amplitudes. Data in conditions of low release probability were also tested for randomness using runs analysis of failures and events (Swed and Eisenhart, 1943) (our Table 2; see footnote 1 for results).

The compound binomial release model assumed that quantal currents were normally distributed and accounted for nonuniformity of both quantal size and release probability. Alternative models based on skewed gamma distributions or models assuming uniformity of quantal size and release probability were also explored, but they generally gave worse fits to the data. The model had the following free parameters: mean quantal size $\langle q\rangle$, intrasite (type 1) coefficient of variation $\mathrm{CV}_{1}$, intersite (type 2) coefficient of variation $\mathrm{CV}_{2}$ (Jack et al., 1994; Walmsley, 1995), mean release probabilities $\langle p\rangle$, and shape factor $\alpha_{\mathrm{p}}$ describing the nonuniformity of individual release probabilities. $\langle q\rangle, \mathrm{CV}_{1}$, and $\mathrm{CV}_{2}$, and $\alpha_{\mathrm{p}}$ were assumed to be the same, whereas $\langle p\rangle$ was specified separately for each condition. The quantal current generated at the $\mathrm{i}$-th site was assumed to follow the distribution $\mathrm{ND}\left(q_{\mathrm{i}}, \sigma^{2}, x\right)$, where $\mathrm{ND}$ is a normal distribution with mean $q_{\mathrm{i}}$ and variance $\sigma^{2}=\left(\mathrm{CV}_{1}<q>\right)^{2}$ (the mean of all $q_{\mathrm{i}}$ values is $<q>$ ), and $\mathrm{x}$ is the current amplitude. If the release probability at the $\mathrm{i}$-th site is denoted as $p_{\mathrm{i}}$ (the mean of all $p_{\mathrm{i}}$ values is $\langle p\rangle$ ), then the compound binomial model for three release sites would be stated as follows.

The probability to observe a failure is:

$$
P_{0}=\left(1-p_{1}\right)\left(1-p_{2}\right)\left(1-p_{3}\right) .
$$



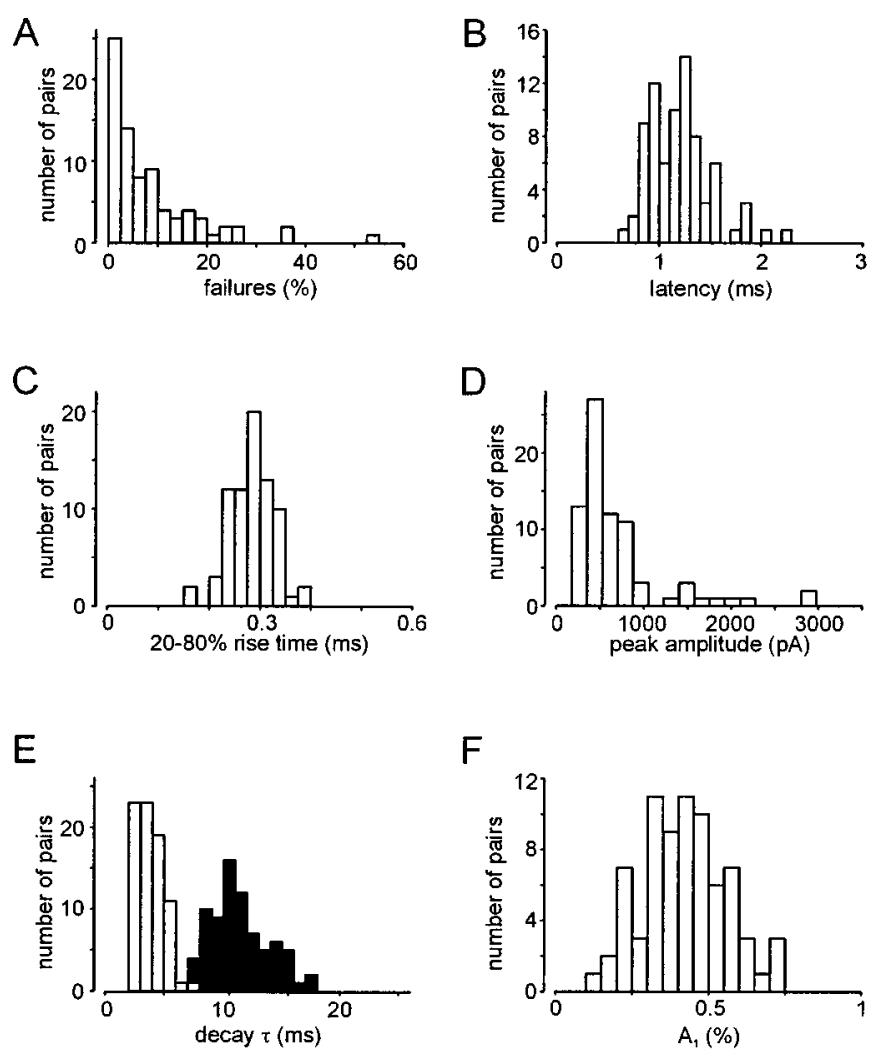

Figure 3. Amplitude and time course of the unitary postsynaptic conductance change at the $\mathrm{BC}-\mathrm{GC}$ synapse. Summary graphs of data from 78 pairs. $A$, Percentage of failures of transmission. $B$, Mean first latency. $C$, Mean $20-80 \%$ rise time. $D$, Mean peak amplitude of average IPSCs (including failures). $E$, Mean decay time constants: fast decay time constant $\tau_{1}$ (open bars); slow decay time constant $\tau_{2}$ (filled bars). $F$, Mean amplitude contribution of the fast component of decay $\left(A_{1}\right)$. Extracellular $\mathrm{Ca}^{2+}$ and $\mathrm{Mg}^{2+}$ concentrations were 2 and $1 \mathrm{mM}$, respectively. Holding potential was $-70 \mathrm{mV}$; intracellular $\mathrm{Cl}^{-}$ concentration in the postsynaptic granule cells was $149 \mathrm{~mm}$ in all experiments.

The amplitude distribution generated by the activation of one of three sites is:

$$
\begin{aligned}
P_{1}(x)= & p_{1}\left(1-p_{2}\right)\left(1-p_{3}\right) \mathrm{ND}\left(q_{1}, \sigma^{2}+\sigma_{0}^{2}, x\right) \\
& +p_{2}\left(1-p_{1}\right)\left(1-p_{3}\right) \mathrm{ND}\left(q_{2}, \sigma^{2}+\sigma_{0}^{2}, x\right) \\
& +p_{3}\left(1-p_{1}\right)\left(1-p_{2}\right) \mathrm{ND}\left(q_{3}, \sigma^{2}+\sigma_{0}^{2}, x\right),
\end{aligned}
$$

where $\sigma_{0}$ is the $\mathrm{SD}$ of the baseline. The amplitude distribution generated by the simultaneous activation of two of three sites is:

$$
\begin{aligned}
P_{2}(x)= & p_{1} p_{2}\left(1-p_{3}\right) \mathrm{ND}\left(q_{1}+q_{2}, 2 \sigma^{2}+\sigma_{0}^{2}, x\right) \\
& +p_{1} p_{3}\left(1-p_{2}\right) \mathrm{ND}\left(q_{1}+q_{3}, 2 \sigma^{2}+\sigma_{0}^{2}, x\right) \\
& +p_{2} p_{3}\left(1-p_{1}\right) \mathrm{ND}\left(q_{2}+q_{3}, 2 \sigma^{2}+\sigma_{0}^{2}, x\right) .
\end{aligned}
$$

Finally, the amplitude distribution generated by the simultaneous activation of all three sites is:

$$
P_{3}(x)=p_{1} p_{2} p_{3} \mathrm{ND}\left(q_{1}+q_{2}+q_{3}, 3 \sigma^{2}+\sigma_{0}^{2}, x\right)
$$

and the total IPSC amplitude distribution can be obtained as:

$$
P(x)=P_{1}(x)+P_{2}(x)+P_{3}(x) .
$$

For $N_{\mathrm{r}}>3$ release sites, the model was extended analogously.

Site-to-site variation of quantal amplitudes $q_{\mathrm{i}}$ was generated using a normal distribution (with mean $\langle q\rangle$ and coefficient of variation $\mathrm{CV}_{2}$ ). Site-to-site variation of release probabilities $p_{\mathrm{i}}$ was implemented using a beta distribution [with mean $<p>$ and shape factor $\alpha_{\mathrm{p}}$ (Silver et al., 1998)]. The $q_{\mathrm{i}}$ and $p_{\mathrm{i}}$ values were obtained by dividing the area under the probability density function into equal portions (the respective areas would be $1 /\left(2 N_{\mathrm{r}}\right), 1 /\left(2 N_{\mathrm{r}}\right)+1 / N_{\mathrm{r}}, 1 /\left(2 N_{\mathrm{r}}\right)+2 / N_{\mathrm{r}}, \ldots, 1-1 /\left(2 N_{\mathrm{r}}\right)$ for $N_{\mathrm{r}}$ release sites). Positive and negative correlations between quantal size and release probability were generated by ranking $q_{\mathrm{i}}$ and $p_{\mathrm{i}}$ values in identical or reverse order, respectively, and the model that gave the better fit was adopted. $\sigma_{0}$ was determined from the region of the baseline preceding the IPSC, with the same settings as those used for determining the peak current.

Estimates of the free parameters of the compound binomial model were obtained by fitting unbinned data by a maximum-likelihood method. The negative logarithm of the likelihood was minimized using a Simplex algorithm (Caceci and Cacheris, 1984) implemented in Pascal, running on $350-600 \mathrm{MHz}$ Pentium PCs. Ranges were defined for each parameter $\left(<q>: 30-500 \mathrm{pA} ; \mathrm{CV}_{1}\right.$ and $\left.\mathrm{CV}_{2}: 0.001-2 ;<p>: 0.01-0.85 ; \alpha_{\mathrm{p}}: 0.01-100\right)$, and the negative log-likelihood was increased when these ranges were exceeded. The final fit results were within the defined parameter space, with the exception of $\alpha_{\mathrm{p}}$, which was frequently at the upper border (100). The criterion for convergence was a relative difference $<10^{-12}$ or $10^{-14}$ in the log-likelihood between best and worst vertex in 10 consecutive iterations (for two and four release conditions, respectively). Within a twofold range of starting values, the final results were relatively insensitive to the initial values. Independent fits were made for different numbers of functional release sites $N_{\mathrm{r}}$ (range: $3-12$ ). $N_{\mathrm{r}}$ was accepted as the best-fit value when the corresponding log-likelihood was larger than that for $N_{\mathrm{r}}-1$ and $N_{\mathrm{r}}+1$, respectively.

Confidence intervals of parameter estimates (see Table 2) were obtained by bootstrap methods. To obtain balanced resampling (Davison et al., 1986; Efron and Tibshirani, 1998), 100 copies of the original data set (size $n$ ) were concatenated, and a random permutation of all $100 * n$ elements was generated. Subsequently, 100 bootstrap replications were read off as successive blocks of length $n$ in the permutated data and were refitted, using the best-fit values for the original data set as initial values (Stricker et al., 1994, 1996). Errors were then estimated from percentile intervals (Efron and Tibshirani, 1998).

Models of vesicular pool dynamics. Synaptic depression during trains of pulses was described by models with two pools (releasable/available and unavailable pool) of synaptic vesicles (Liu and Tsien, 1995a,b; Weis et al., 1999; Matveev and Wang, 2000):

$$
\begin{aligned}
\text { pool }_{1} & \stackrel{p_{\mathrm{R}}\left(N_{\mathrm{v}}\right) f}{\longrightarrow} \text { pool }_{2}, \\
(\text { releasable }) & \stackrel{\text { unavailable })}{\longleftarrow}
\end{aligned}
$$

where $p_{\mathrm{R}}\left(N_{\mathrm{v}}\right)$ is the release probability, $k$ is the rate of refilling of the releasable pool, $f$ is the stimulation frequency, and $N_{\mathrm{v}}$ is the number of vesicles in the releasable pool at any point in time, with initial value and upper limit $N_{v 0}$ (the "capacity" of the releasable pool). The stochastic implementation of the model assumed a univesicular release constraint in response to a presynaptic action potential (Korn et al., 1982). The release probability was $p_{\mathrm{R}}\left(N_{\mathrm{v}}\right)=1-\exp \left(-\alpha_{\mathrm{v}} N_{\mathrm{v}}\right)$, where $\alpha_{\mathrm{v}}$ denotes the timeintegrated fusion rate for a single vesicle (Dobrunz and Stevens, 1997; Matveev and Wang, 2000). The probability of refilling of each vacancy in the releasable pool in the time interval $\Delta t=1 / f$ between two consecutive stimuli was $p_{\text {Refill }}=1-\exp (-k \Delta t)$ (Matveev and Wang, 2000). $p_{\mathrm{R}}$ during and after high-frequency stimulation was computed by averaging the results from 1000 Monte-Carlo simulations, using programs written in Pascal.

Activity-dependent decrease of release probability and increase of refilling rate were modeled as the activation of a two-state modification process:

$$
\text { resting } \underset{\beta}{\stackrel{\alpha f}{\longleftarrow}} \text { activated, }
$$

where $\alpha$ and $\beta$ denote forward and backward rates of the modification. The fractional occupancy $a(t)$ of the activated state was calculated from the equations:

$$
\begin{gathered}
a(t)=a_{\infty}-\left(a_{\infty}-a_{0}\right) \exp (-t / \tau), \text { with } \\
a_{\infty}=\alpha f /(\alpha f+\beta) \text { and } \\
\tau=1 /(\alpha f+\beta),
\end{gathered}
$$

where $a_{0}$ and $a_{\infty}$ indicate initial and final values of $a(t)$ during the stimulation and recovery period. Activity-dependent decreases of release probability and increases in refilling rate were implemented as:

$$
\begin{gathered}
p_{\mathrm{R}}^{\prime}=p_{\mathrm{R}}\left[1-a_{\max } a(t)\right], \text { with } 1 \geq a_{\max } \geq 0, \text { and } \\
k^{\prime}=k\left[1+a_{\max } a(t)\right], \text { with } a_{\max } \geq 0,
\end{gathered}
$$

where $a_{\max }$ indicates the maximal modification. Thus the activitydependent pool models had the following free parameters: pool capacity $N_{\mathrm{v} 0}$, initial release probability $p_{\mathrm{R}}$, refilling rate $k$, maximal modification $a_{\mathrm{max}}$, and rates of activity-dependent modification $\alpha$ and $\beta$. Parameters of the pool model were specified arbitrarily (see Fig. 10). Alternatively, estimates of the parameters of the pool model were obtained using a least-squares method, minimizing the sum of squares of differences between experimental observations and model predictions with a Simplex 
Table 1. Summary of functional properties of unitary IPSCs generated at the BC-GC synapse

\begin{tabular}{|c|c|}
\hline & Mean \pm SEM [range] $(n)$ \\
\hline Latency IPSC ${ }^{a}$ & $1.13 \pm 0.04 \mathrm{msec}[0.58-2.80](78)$ \\
\hline $20-80 \%$ rise time of IPSC ${ }^{a}$ & $0.26 \pm 0.01 \mathrm{msec}[0.13-0.51](78)$ \\
\hline Decay $\tau_{1}$ of IPSC ${ }^{a}$ & $1.9 \pm 0.1 \mathrm{msec}[0.4-5.3](78)$ \\
\hline Decay $\tau_{2}$ of IPSC ${ }^{a}$ & $9.4 \pm 0.3 \operatorname{msec}[4.3-16.0](78)$ \\
\hline Amplitude contribution fast component ${ }^{a}$ & $38.1 \pm 1.6 \%[9.3-69.5](78)$ \\
\hline Peak amplitude IPSC (including failures) ${ }^{a}$ & $504 \pm 54 \mathrm{pA}[110-2650](78)$ \\
\hline Percentage of failures $\left(2 \mathrm{mM} \mathrm{Ca}^{2+}, 1 \mathrm{mM} \mathrm{Mg}^{2+}\right)$ & $6.5 \pm 1.0 \%[0-51.2](78)$ \\
\hline Peak amplitude of quantal IPSCs & $129 \pm 19 \mathrm{pA}[84-176](5)$ \\
\hline $\mathrm{CV}$ of quantal IPSCs $\left(0.1-0.3 \mathrm{mM} \mathrm{Ca}^{2+}\right)^{b}$ & $33.7 \pm 1.0 \%[31.5-37.0](5)$ \\
\hline Decay $\tau$ of release period ${ }^{c}$ & $0.23 \mathrm{msec}[0.16-0.27](4)$ \\
\hline \multicolumn{2}{|l|}{ PPD } \\
\hline Maximum depression (at $10 \mathrm{msec}$ ) & $37 \pm 6 \%[17-46](10)$ \\
\hline Recovery $\tau$ & $1.97 \sec (3-11)$ \\
\hline \multicolumn{2}{|l|}{ Multiple-pulse depression $(20 \mathrm{~Hz}, 1000$ action potentials $)$} \\
\hline Onset $\tau_{1}$ control & $61 \mathrm{msec}(55 \%)(23)$ \\
\hline Onset $\tau_{2}$ & $17.6 \sec (26 \%)(23)$ \\
\hline Recovery $\tau_{1}$ & $1.3 \sec (48 \%)(23)$ \\
\hline Recovery $\tau_{2}$ & $31.7 \sec (36 \%)(23)$ \\
\hline Onset $\tau_{1} 5 \mu \mathrm{M}$ CGP55845A & $147 \mathrm{msec}(53 \%)(7)$ \\
\hline Onset $\tau_{2}$ & $10.9 \sec (21 \%)(7)$ \\
\hline Train-induced depression, critical frequency ${ }^{d}$ & $5.0 \mathrm{~Hz}(23)$ \\
\hline Reversal potential unitary IPSCs $\left(6 \mathrm{~mm}\right.$ intracellular $\left.\mathrm{Cl}^{-}\right)$ & $-71.4 \mathrm{mV}(2)$ \\
\hline Reversal potential compound IPSCs (gramicidin-perforated patch) ${ }^{e}$ & $-71.9 \pm 1.9 \mathrm{mV}(3)$ \\
\hline Reversal potential unitary IPSCs $\left(149 \mathrm{~mm}\right.$ intracellular $\left.\mathrm{Cl}^{-}\right)$ & $+4.2 \pm 0.6 \mathrm{mV}(3)$ \\
\hline Block of unitary IPSCs by $10 \mu \mathrm{M}$ bicuculline methiodide & $96 \pm 1.1 \%(5)$ \\
\hline
\end{tabular}

${ }^{a}$ Values were determined from average IPSCs.

${ }^{b}$ Corrected for baseline noise.

${ }^{c}$ Decay $\tau$ of release period was determined from the first latency distribution according to Barrett and Stevens (1972).

${ }^{d}$ Frequency that results in half-maximal depression in the steady state.

${ }^{e}$ In perforated-patch experiments, the access resistance was 50-100 $\mathrm{M} \Omega$.

algorithm. Weights were chosen arbitrarily according to inverse of variance of data points, numbers of experiments, and number of data points in each set (see Fig. 9C-E,H).

\section{RESULTS}

\section{Unitary IPSPs and IPSCs at the BC-GC synapse}

We examined inhibitory synaptic transmission between pairs of monosynaptically connected BCs and GCs in slices from mature rats $(18-25 \mathrm{~d}$ old $)$ at physiological temperatures $\left(34^{\circ} \mathrm{C}\right)$. This synapse has several technical advantages (Fig. 1). First, interneurons and principal neurons in this circuit can be distinguished by morphological criteria (Fig. $1 A$ ) and by the ability of the presynaptic interneuron to generate high-frequency trains of action potentials during sustained current injection (Fig. $1 B$ ). Second, paired recordings from synaptically connected interneurons and principal neurons can be obtained with relatively high probability, because the axonal arborization of BCs is extensive (Fig. 1 $A$ ) (Freund and Buzsáki, 1996; Geiger et al., 1997). Third, although unitary IPSPs and IPSC s have small amplitudes at physiological intracellular $\mathrm{Cl}^{-}$ concentrations (Fig. $1 C, D$ ), the amplitude of unitary IPSCs with high intracellular $\mathrm{Cl}^{-}$concentration $(149 \mathrm{~mm})$ is substantially larger, with excellent signal-to-noise ratio under these conditions (Fig. 1E). Fourth, the voltage-clamp conditions of the unitary IPSCs are ideal, because of the mainly perisomatic location of synaptic contacts and the favorable electrotonic properties of postsynaptic granule cells. Finally, synaptic transmission in the paired recording configuration is stationary over long periods of time, with a stimulation frequency of $\leq 0.25 \mathrm{~Hz}$ (Fig. $1 F)$.

Figure 2 shows the properties of unitary IPSCs in high intracellular $\mathrm{Cl}^{-}$in an individual pair, and Figure 3 summarizes the results from $78 \mathrm{BC}-\mathrm{GC}$ pairs. The mean synaptic latency, measured from the steepest point in the rising phase of the presynaptic action potential to the onset of the IPSC, was $1.1 \mathrm{msec}$. The rise of the synaptic events was almost instantaneous (average $20-80 \%$ rise time $0.26 \mathrm{msec}$ ). The mean unitary IPSC peak amplitude (including failures of transmission) was $504 \mathrm{pA}$ at $-70 \mathrm{mV}$. Because the mean reversal potential of unitary IPSCs is $+4.2 \mathrm{mV}$ (Table 1 ), this corresponds to a peak conductance change of $6.8 \mathrm{nS}$. The decay of the unitary IPSCs was better fitted with the sum of two exponentials than with a single exponential in the majority of pairs; the average values of the time constants were $1.9 \mathrm{msec}$ (38\% amplitude contribution) and $9.4 \mathrm{msec}$, respectively. Synaptic transmission at the $\mathrm{BC}-\mathrm{GC}$ synapse was very reliable; the mean percentage of failures was $6.5 \%$. Thus BC-mediated inhibition shows short latency, rapid onset, large peak-conductance change, long duration, and high reliability (Table 1 ).

\section{Direct recording of quantal IPSCs at the BC-GC synapse}

Rigorous analysis of the transmitter release process requires direct recording of quantal currents (Katz, 1969; Isaacson and Walmsley, 1995). We therefore examined quantal BC-GC IPSCs in conditions of low release probability with a reduced $\mathrm{Ca}^{2+} / \mathrm{Mg}^{2+}$ concentration ratio in the bath solution (Fig. 4). Figure 4, $A$ and $B$, shows unitary IPSCs in a pair at two different $\mathrm{Ca}^{2+} / \mathrm{Mg}^{2+}$ concentrations. When the $\mathrm{Ca}^{2+} / \mathrm{Mg}^{2+}$ concentration ratio was reduced, the amplitude of the unitary IPSC decreased, and the number of failures increased substantially, to $>80 \%$ with $\mathrm{Ca}^{2+}$ concentrations $<0.5 \mathrm{~mm}$ (Fig. $4 C$ ). Under these conditions, the amplitude of the successful unitary IPSCs excluding failures reached an asymptotic value corresponding to the quantal size (Fig. $4 D$ ). The mean peak amplitude of these putative quantal IPSCs was $129 \pm 19 \mathrm{pA}$ at $-70 \mathrm{mV}$. With the mean reversal potential of unitary IPSCs of $+4.2 \mathrm{mV}$, this corresponds to an apparent quantal 


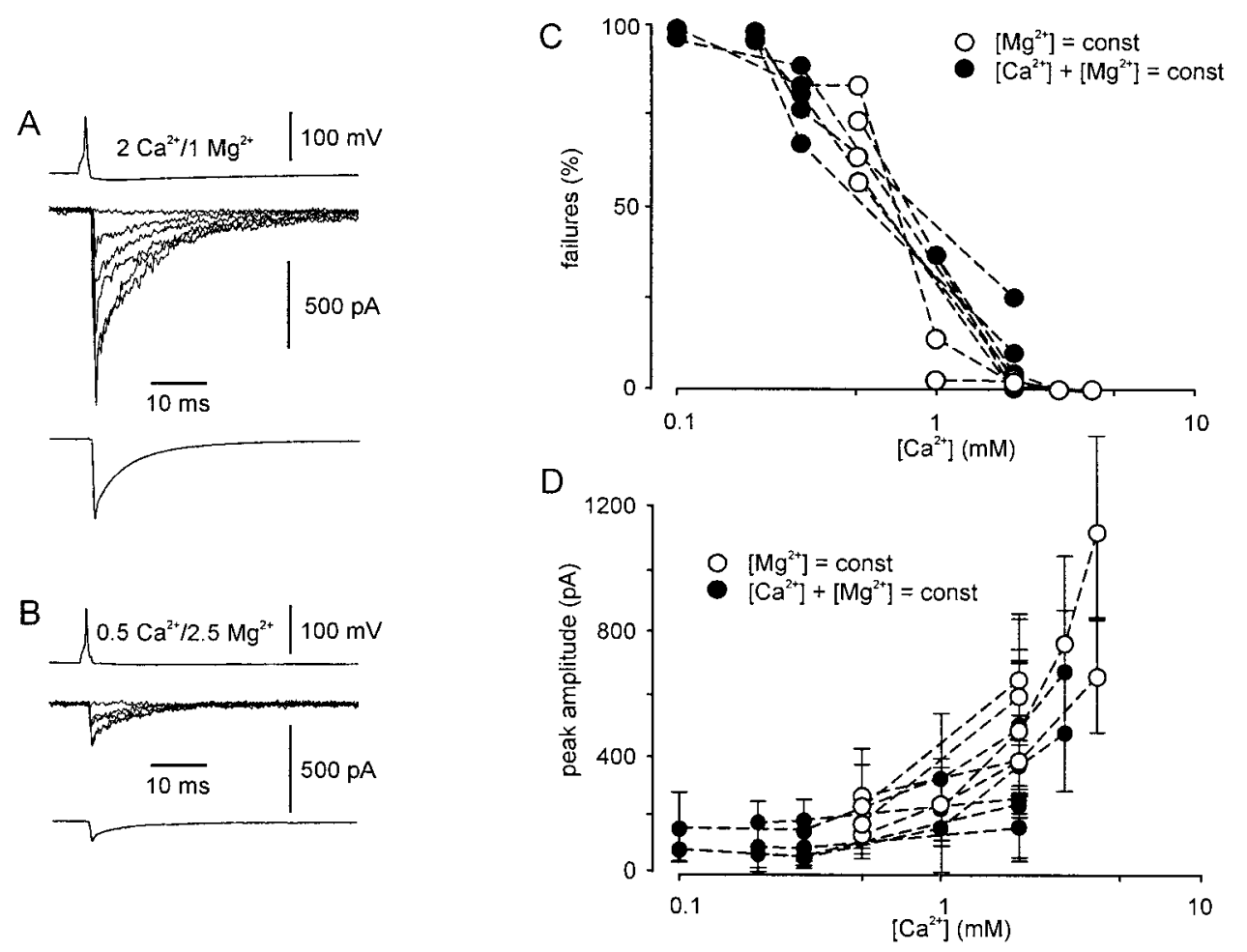

Figure 4. Direct recording of quantal IPSCs at the $\mathrm{BC}-\mathrm{GC}$ synapse. $A, B$, Unitary IPSCs at physiological $\mathrm{Ca}^{2+} / \mathrm{Mg}^{2+}$ concentrations (A) $\left(2 \mathrm{mM} \mathrm{Ca}^{2+}, 1 \mathrm{mM} \mathrm{Mg}^{2+}\right)$ and after reduction of release probability $(B)(0.5 \mathrm{~mm}$ $\left.\mathrm{Ca}^{2+}, 2.5 \mathrm{mM} \mathrm{Mg}^{2+}\right)$. Six traces are shown superimposed on top; average IPSCs including failures are shown at the bottom. $C$, Percentage of failures plotted against the extracellular $\mathrm{Ca}^{2+}$ concentration. $D$, Mean peak amplitude of successful IPSCs (excluding failures) plotted against extracellular $\mathrm{Ca}^{2+}$ concentration. Error bars indicate SD of IPSC amplitudes. Open circles indicate experiments in which the $\mathrm{Mg}^{2+}$ concentration was kept constant ( 3 or $4 \mathrm{~mm}$ ); filled circles represent experiments in which the sum of $\mathrm{Ca}^{2+}$ and $\mathrm{Mg}^{2+}$ concentrations was maintained $(3 \mathrm{mM})$. As the $\mathrm{Ca}^{2+}$ concentration was reduced, the number of failures increased, but the amplitude of the successful IPSCs approached asymptotically a minimal value. This suggests that IPSCs at $\mathrm{Ca}^{2+}$ concentrations below 0.5 mM are mainly quantal IPSCs. Data in $C$ and $D$ are from 11 pairs; data obtained from the same pair were connected by dashed lines. conductance change of $1.7 \pm 0.3 \mathrm{nS}$. The mean $\mathrm{CV}$ of the putative quantal IPSC in conditions of low release probability, including both intrasite and intersite components, was $33.7 \pm 1.0 \%$ (five pairs at $\mathrm{Ca}^{2+}$ concentrations of $0.1-0.3 \mathrm{~mm}$, corrected for baseline noise). Thus direct recording of quantal IPSCs at the BC-GC synapse reveals a large quantal size and a moderate variability of the quantal amplitude.

\section{The time course of quantal release}

Asynchrony of transmitter release can provide a significant contribution to the time course of the average postsynaptic conductance change at various synapses (Diamond and Jahr, 1995; Isaacson and Walmsley, 1995; Geiger et al., 1997). To determine the time course of quantal release at the $\mathrm{BC}-\mathrm{GC}$ synapse, we used the approach of first latency measurements (Barrett and Stevens, 1972) (Fig. 5). The time course of quantal release (open bars), determined from the distribution of first latencies (filled bars) in conditions of reduced $\mathrm{Ca}^{2+} / \mathrm{Mg}^{2+}$ concentration ratio, rose and decayed within a time window of $\sim 1 \mathrm{msec}$, indicating that GABA release was highly synchronized (Fig. $5 A$ ). To test the validity of the first latency approach, single quantal events in low $\mathrm{Ca}^{2+} / \mathrm{Mg}^{2+}$ concentration ratio were aligned to their onset, averaged, and reconvolved with the time course of quantal release in the same pair. The time course of the reconvolved IPSC was almost indistinguishable from that of the averaged unitary IPSC (four pairs), suggesting that quantal contributions superimposed independently (Fig. $5 B$ ). The logarithmic plot of the mean time course of release from four pairs illustrates that the release period decayed approximately exponentially, with a time constant of $0.23 \mathrm{msec}$ (Fig. $5 C$ ). Thus quantal release at the $\mathrm{BC}-\mathrm{GC}$ synapse showed high synchrony, comparable to that of fast excitatory synapses (Isaacson and Walmsley, 1995; Geiger et al., 1997).

To further examine the possibility of cross talk (Barbour and Häusser, 1997) or multivesicular release (Auger et al., 1998) at higher release probabilities, we tested whether the decay time course of average unitary IPSC s became slower as the $\mathrm{Ca}^{2+} / \mathrm{Mg}^{2+}$ concentration ratio was increased. IPSCs in conditions of normal and reduced $\mathrm{Ca}^{2+} / \mathrm{Mg}^{2+}$ concentration ratio, normalized to their respective peak current amplitudes, showed almost identical time courses (Fig. $5 D$ ). The mean decay time constant was very similar for $\mathrm{Ca}^{2+}$ concentrations between 0.1 and $2 \mathrm{~mm}$, with only a slight prolongation at higher concentrations (Fig. 5E; 2-12 pairs per $\mathrm{Ca}^{2+}$ concentration). Furthermore, as indicated by the scatter plot from individual evoked IPSCs, the decay time constant was independent of the IPSCs amplitude (Fig. $5 F$; four pairs). Thus the analysis of the decay time course of IPSCs provides no evidence for cross talk or increase in the number of fused vesicles with increasing $\mathrm{Ca}^{2+}$ concentration at this synapse.

\section{Number of functional release sites and release probability}

Because a decrease of the $\mathrm{Ca}^{2+} / \mathrm{Mg}^{2+}$ concentration ratio reduced the amplitude of the IPSCs excluding failures (Fig. 4), it appeared likely that the $\mathrm{BC}-\mathrm{GC}$ synapse comprises multiple functional release sites. To determine the number of functional release sites and the probability of release at individual sites quantitatively, we fitted IPSC peak amplitude distributions at different $\mathrm{Ca}^{2+} / \mathrm{Mg}^{2+}$ concentration ratios with compound binomial models of release (MP-CBA; see Materials and Methods) (Fig. 6) (Redman, 1990). Failures were also included in the fit because (1) they could be unequivocally distinguished from successful IPSCs because of the favorable recording conditions and (2) they appeared to be entirely failures of synaptic transmission (stimulation failures were not present in the paired recording configuration, and conduction failures appeared unlikely; see Discussion).

Two examples are shown in Figure 6, with amplitude distributions in $2 \mathrm{mM} \mathrm{Ca}^{2+} / 1 \mathrm{~mm} \mathrm{Mg}^{2+}$ on top and in $0.5 \mathrm{mM} \mathrm{Ca}^{2+} / 2.5 \mathrm{~mm}$ $\mathrm{Mg}^{2+}$ at the bottom. The estimated number of functional release sites was seven and five, and the mean release probability in $2 \mathrm{~mm}$ $\mathrm{Ca}^{2+} / 1 \mathrm{mM} \mathrm{Mg}^{2+}$ was 0.61 and 0.57 , respectively. Bootstrap analysis further indicated that the errors in the estimates of number of functional release sites and release probability were small for both pairs (Fig. 6C, Table 2).

In five pairs in which IPSC amplitudes, rise times, and series resistance were stationary and the total number of traces was $>700$, the number of functional release sites estimated by MP-CBA ranged from three to seven, and the mean release probability in physiological divalent concentrations was between 0.41 and 0.63 (Table 2). In all pairs both intrasite (Liu and Tsien, 1995a) and intersite (Nusser et al., 1997) components of quantal variability appeared to be present. Although the compound binomial model accounted for inhomogeneity of release probability in principle, 
Figure 5. Time course of quantal release at the $\mathrm{BC}-\mathrm{GC}$ synapse. $A$, First latency distribution ( filled bars) and time course of quantal release (open bars) in a BC-GC pair, calculated from first latencies using the correction method of Barrett and Stevens (1972). Data were obtained with $0.5 \mathrm{mM} \mathrm{Ca}^{2+}$ and $2.5 \mathrm{~mm}$ $\mathrm{Mg}^{2+}$ in the bath; data are from 299 IPSCs (401 failures). $B$, Average unitary IPSC in 0.5 $\mathrm{mM} \mathrm{Ca}{ }^{2+}, 2.5 \mathrm{~mm} \mathrm{Mg}{ }^{2+}$, average quantal IPSC (obtained after aligning single events on their rising phase), and a simulated IPSC generated by reconvolution of the time course of quantal release with the time course of the quantal conductance change are shown superimposed. The three traces were normalized to the same peak value. $C$, Mean time course of quantal release. Histograms of the time course of release were aligned to the bin with the maximal number of events $\left(n_{\max }\right.$, which is represented as time 0 in the graph). Numbers of events were normalized by $n_{\max }$ and plotted logarithmically. The line represents the results of linear regression of the decay, yielding a decay time constant of 0.23 msec. Data are from four pairs. $D$, Average unitary IPSCs in 2 $\mathrm{mM} \mathrm{Ca}^{2+} / 1 \mathrm{mM} \mathrm{Mg}^{2+}$ and $0.5 \mathrm{mM} \mathrm{Ca}^{2+} / 2.5$ $\mathrm{mM} \mathrm{Mg}^{2+}$, normalized to the same peak amplitude value, are shown superimposed. The absolute peak amplitudes were 612 and 164 $\mathrm{pA}$, respectively. $E$, Plot of the decay time constants against extracellular $\mathrm{Ca}^{2+}$ concentration: fast decay time constant $\tau_{1}$ (open symbols), slow decay time constant $\tau_{2}$ (filled symbols); different symbol shape indicates different pairs (12 total). The graph illustrates that the decay time course of the IPSCs is only weakly dependent on extracellular $\mathrm{Ca}^{2+}$ concentration. $F$, Plot of the decay time constants (mean value of the two time constant values weighted with the respective amplitude contribution) of single unitary IPSCs in four pairs against the peak amplitudes. Both weighted time constant and amplitude were normalized to the mean value in the recorded ensemble. Line represents the results of linear regression. No significant correlation between time constant and amplitude was apparent $(p>0.1)$. Data in $A$ $B$, and $D$ are from the same pair.
A

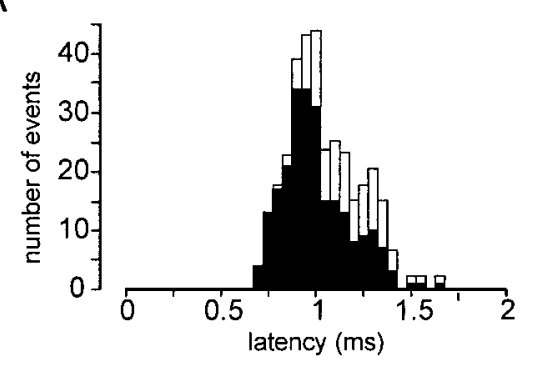

B
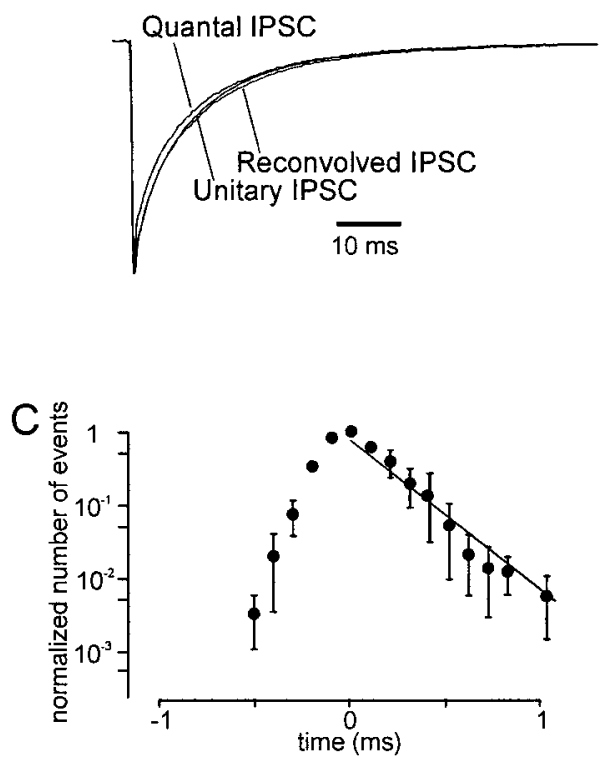

D $\curlywedge$ $100 \mathrm{mV}$

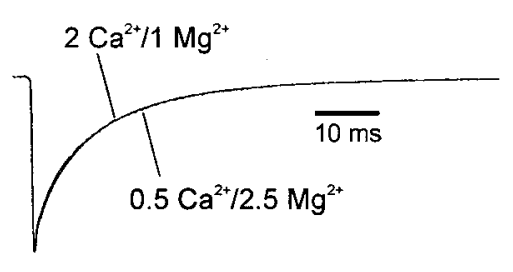

E
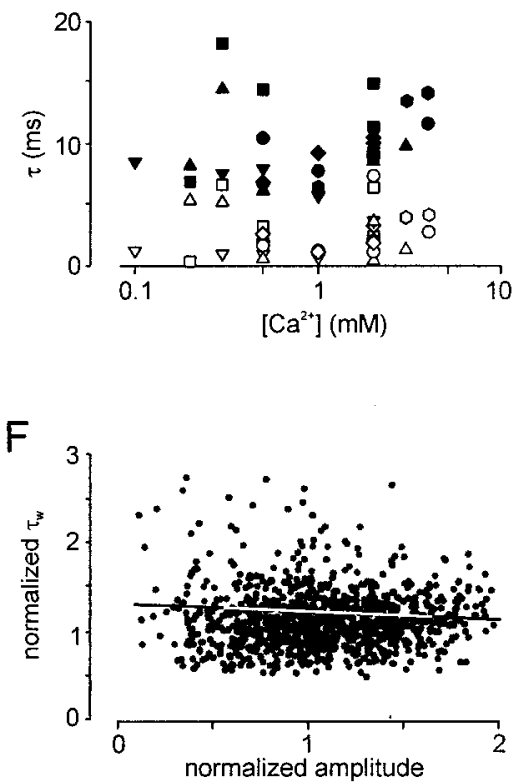

the high value of the shape parameter $\alpha_{\mathrm{p}}\left(10^{1.4}-10^{2}\right)$ (Table 2) indicated that the release probability was relatively uniform among sites (Silver et al., 1998).

MP-CBA further allowed us to investigate the dependence of the estimated mean release probability on extracellular $\mathrm{Ca}^{2+}$ concentration, as shown in Figure $6 D$. Fitting the data with a Hill equation revealed a half-maximal release probability at a $\mathrm{Ca}^{2+}$ concentration of $1.5 \mathrm{~mm}$, an apparent Hill coefficient of 2.4, and an extrapolated maximal release probability of 0.79 . Fitting the data at the low-concentration limit $(\leq 1 \mathrm{~mm})$ in double logarithmic representation gave similar results (apparent Hill coefficient 2.5; fit results not illustrated). In conclusion, single action potentials in the presynaptic BC trigger powerful inhibition of the postsynaptic GC, attributable to a large quantal size, a high release probability at physiological $\mathrm{Ca}^{2+}$ concentrations, and the presence of multiple functional release sites.

\section{Depression induced by paired-pulse stimulation}

In the intact hippocampal network, BCs can generate highfrequency trains of action potentials (Penttonen et al., 1998; Csicsvari et al., 1999). This raises the question of whether dynamic changes of transmission occur at $\mathrm{BC}-\mathrm{GC}$ synapses during repetitive stimulation. We first examined paired-pulse modulation (Fig. 7). When two action potentials were elicited in the BC, separated by intervals of variable duration, the amplitude of the second IPSC was smaller than that of the first (Fig. $7 A$ ). The maximal pairedpulse depression, measured for $10 \mathrm{msec}$ interpulse intervals, was $37 \pm 6 \%$. Recovery from PPD was complete after $5 \mathrm{sec}$; when fitted with a single exponential function, the time constant of recovery was $1.97 \mathrm{sec}$ (Fig. 7B) (3-11 pairs).
To determine whether the depression was presynaptic or postsynaptic in origin, we examined the variation of peak current amplitudes during the first and second IPSC for interpulse intervals of $\geq 100 \mathrm{msec}$. Figure $7 C$ shows a summary plot of the inverse of the square of the $\mathrm{CV}\left(\mathrm{CV}^{-2}\right)$ against the mean amplitudes of the second IPSC (nine pairs); both $\mathrm{CV}^{-2}$ and mean were normalized to the values of the first IPSC (Malinow and Tsien, 1990). The data points were superimposed with the predictions of a model with variable presynaptic and postsynaptic contributions to PPD, using Equation 8 of Silver et al. (1998) and mean values for $N_{\mathrm{r}},\langle p\rangle$, $\mathrm{CV}_{1}$, and $\mathrm{CV}_{2}$ as obtained by MP-CBA (Table 2). A comparison of data points and model curves suggests that the results were more consistent with a reduction in $\langle p\rangle$ than a reduction in $\langle q\rangle$, implying that PPD was mainly presynaptic in origin.

If PPD was caused by the activation of presynaptic $\mathrm{GABA}_{\mathrm{B}}$ receptors (Deisz and Prince, 1989; Lambert and Wilson, 1994) after release of GABA from a single $\mathrm{BC}$, it should be blocked by the selective, high-affinity $\mathrm{GABA}_{\mathrm{B}}$ receptor antagonist CGP55845A (Kaupmann et al., 1997); however, PPD for $100 \mathrm{msec}$ intervals was not significantly different in the absence and presence, respectively, of $5 \mu \mathrm{M}$ CGP55845A (Fig. $7 D)(p>0.2)$, indicating that $\mathrm{PPD}$ is independent of presynaptic $\mathrm{GABA}_{\mathrm{B}}$ receptor activation.

If PPD was caused by depletion of the releasable pool of synaptic vesicles (Stevens and Tsujimoto, 1995; Debanne et al., 1996; Dobrunz and Stevens, 1997), its extent should be dependent on the average release probability. In contrast to this prediction, the extent of PPD at the BC-GC synapse was not significantly different in various $\mathrm{Ca}^{2+} / \mathrm{Mg}^{2+}$ concentration ratios (Fig. $\left.8 A\right)(p>0.2)$. 
Aa

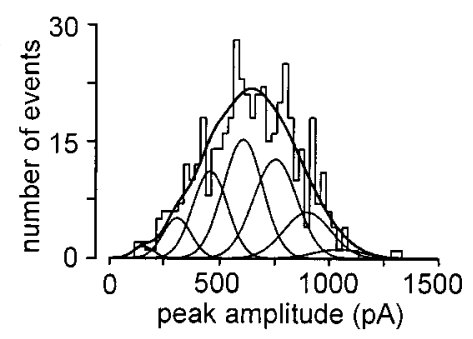

$b$

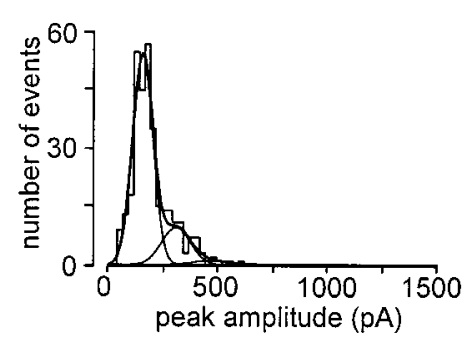

$\mathrm{Ca}$
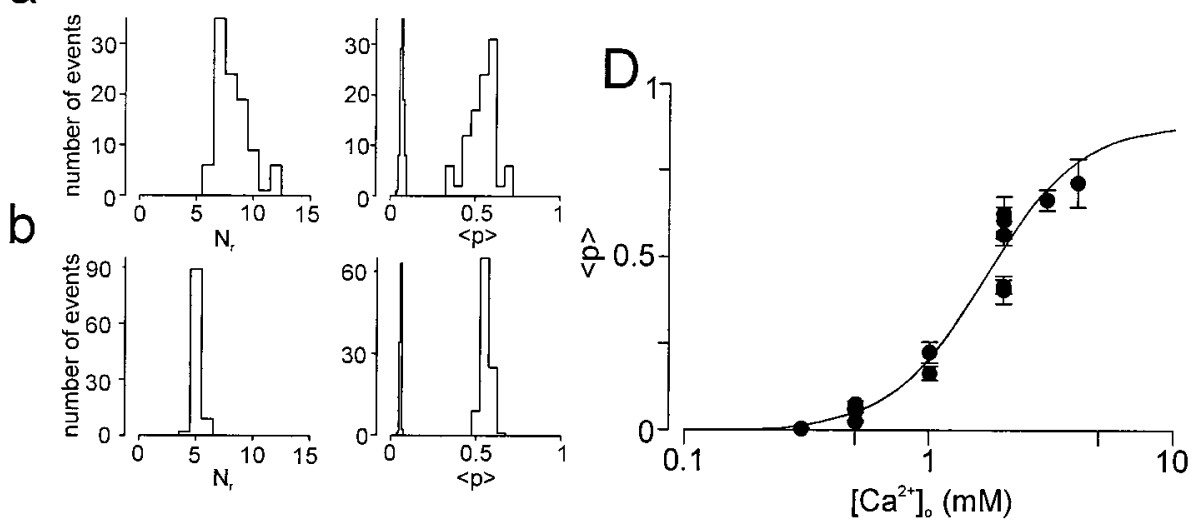

Figure 6. Estimation of the number of functional release sites and the release probability using multiple probability compound binomial analysis. $A$, Peak amplitude distributions from a pair in $2 \mathrm{mM} \mathrm{Ca}{ }^{2+} / 1 \mathrm{mM} \mathrm{Mg}^{2+}(a)$ and 0.5 $\mathrm{mM} \mathrm{Ca}{ }^{2+} / 2.5 \mathrm{mM} \mathrm{Mg}^{2+}(b)$. The thick curve represents the total probability density function $\left(\Sigma P_{\mathrm{i}}(x)\right)$; the thin curves represent individual components $\left(P_{1}(x)-P_{7}(x)\right)$ as obtained by maximum-likelihood fit. For model parameters, see Table 2, pair \#1. Failures are not depicted; measured numbers of failures were 1 ( $a)$ and $430(b)$, and predicted numbers of failures were $1(a)$ and $429(b)$. B, Similar analysis for a different pair (\#3) in $2 \mathrm{~mm}$ $\mathrm{Ca}^{2+} / 1 \mathrm{mM} \mathrm{Mg}^{2+}(a)$ and $0.5 \mathrm{mM} \mathrm{Ca}^{2+} / 2.5$ $\mathrm{mM} \mathrm{Mg}{ }^{2+}(b)$. Measured numbers of failures were $13(a)$ and $731(b)$, and predicted numbers of failures were $8(a)$ and $729(b) . C$, Results of bootstrap analysis for the number of functional release sites (left) and the release probabilities in the two conditions (right) for pair \#1 $(a)$ and pair \#3 $(b)$. Bootstrap replications (100) of the original data set were fitted in a manner identical to the original data set, and the distributions of estimated number of release sites and release probabilities (in $2 \mathrm{mM}$ $\mathrm{Ca}^{2+} / 1 \mathrm{mM} \mathrm{Mg}^{2+}$ and $0.5 \mathrm{mM} \mathrm{Ca}^{2+} / 2.5 \mathrm{~mm}$ $\mathrm{Mg}^{2+}$, respectively) were plotted. For details, see Materials and Methods. D, Plot of estimated mean release probability $\langle p\rangle$ against extracellular $\mathrm{Ca}^{2+}$ concentration for the five pairs shown in Table 2. Data were fitted with a Hill equation $f(c)=p_{\max }\left[1+\left(\mathrm{EC}_{50} / c\right)^{\mathrm{n}}\right]^{-1}$, with maximal release probability $p_{\max }=0.79$, $\mathrm{EC}_{50}=1.5 \mathrm{~mm}$, and apparent Hill coefficient $n=2.4$, where $c$ denotes the extracellular $\mathrm{Ca}^{2+}$ concentration.
Furthermore, if PPD was caused by depletion, the peak amplitude of the second IPSC evoked by paired stimulation should be inversely related to that of the first (Debanne et al., 1996); however, amplitudes of IPSCs evoked by paired stimuli were not significantly correlated at the BC-GC synapse (Fig. $8 B$ ). Thus PPD at the $\mathrm{BC}-\mathrm{GC}$ synapse was presynaptic in origin, but unexpectedly appeared to be independent of both extracellular $\mathrm{Ca}^{2+}$ concentration and previous release.

\section{Depression induced by multiple-pulse stimulation}

We then examined dynamic changes of transmission at the $\mathrm{BC}-\mathrm{GC}$ synapse during $1-50 \mathrm{~Hz}$ trains of 900-1000 action potentials (Fig. 9). Evoked IPSCs at the BC-GC synapse showed a marked depression during high-frequency stimulation, as reported previously for inhibitory synapses in the neocortex (Galarreta and Hestrin, 1998; Varela et al., 1999). The onset of depression was biexponential, with time constants of $61 \mathrm{msec}$ and $17.6 \mathrm{sec}$ for a stimulation frequency of $20 \mathrm{~Hz}$ (Fig. 9C) (23 pairs). The steady-state depression increased with the frequency of stimulation; half-maximal depression occurred at $5.0 \mathrm{~Hz}$ (Fig. 9D). After a $20 \mathrm{~Hz}$ train of action potentials, recovery from depression was biexponential, with time constants of 1.3 and $31.7 \mathrm{sec}$ (Fig. 9E) (23 pairs).

To determine whether the depression was presynaptic or postsynaptic in origin, $\mathrm{CV}^{-2}$ was plotted against the mean unitary IPSC in steady-state conditions at a given frequency; both $\mathrm{CV}^{-2}$ and mean were normalized to the control values at $0.25 \mathrm{~Hz}$ (Fig. $9 F)$. The data points were superimposed with the predictions of a model with variable presynaptic and postsynaptic contributions to depression (Fig. $7 C$ ). Similar to PPD, comparison of data and predictions suggests that multiple-pulse depression was mainly presynaptic in origin. In the presence of $5 \mu \mathrm{M}$ CGP55845A, the time course of depression was qualitatively similar, but the steady-state
IPSC amplitude was significantly larger (33 $\pm 6 \%$ vs $21 \pm 2 \%, p<$ 0.01 ) (Fig. $9 G$ ) (seven pairs), suggesting a small contribution of $\mathrm{GABA}_{\mathrm{B}}$ receptors to multiple-pulse depression.

Frequency-dependent depression is often interpreted as a depletion of the releasable pool of synaptic vesicles (Liley and North, 1953; Stevens and Tsujimoto, 1995). If this were the case, its extent would depend on the average release probability (Dittman and Regehr, 1998), and amplitudes of consecutive IPSCs in the train may be correlated (Matveev and Wang, 2000). We therefore examined depression during $20 \mathrm{~Hz}$ trains at different $\mathrm{Ca}^{2+} / \mathrm{Mg}^{2+}$ concentration ratios (Fig. $9 H$ ). In conditions of reduced release probability $\left(0.5 \mathrm{mM} \mathrm{Ca}^{2+}\right)$, the fast component of depression was comparable, but the slow component showed a reduced amplitude and a slower time course (Fig. 9H, open symbols). The ratio of currents at the end of the train to those before the train was significantly larger in $0.5 \mathrm{mM} \mathrm{Ca}^{2+}(0.55 \pm 0.08)$ than in $2 \mathrm{~mm}$ $\mathrm{Ca}^{2+}(0.27 \pm 0.03 ; p<0.001)$. Furthermore, amplitudes of subsequent IPSCs in the second portion of the train were negatively correlated (Fig. 9I). These results are consistent with the hypothesis that the slow component of depression is caused by depletion of the vesicular pool (Matveev and Wang, 2000).

To understand the interactions between fast and slow depression, we examined the quantitative predictions of pool models with different forms of activity dependence (Betz, 1970; Kusano and Landau, 1975). Figure 10 illustrates the predictions of a two-pool model with constant release probability and replenishment (Fig. 10, model $a$ ) and two alternative models with either activity-dependent reduction in release probability (model $b$ ) or activity-dependent increase in replenishment (model $c)$. In the absence of evidence for multivesicular release (Fig. 5), we implemented a univesicular release constraint (Korn et al., 1982; Matveev and Wang, 2000). 
Table 2. Number of release sites and release probability at the BC-GC synapse determined by MP-CBA

\begin{tabular}{|c|c|c|c|c|c|c|c|c|c|}
\hline Pair $^{a}$ & $\mathrm{Ca}^{2+} / \mathrm{Mg}^{2+}(\mathrm{mM})$ & Events & Failures $^{b}$ & $N_{\mathrm{r}}$ & $\langle p\rangle^{c, e}$ & $\langle q\rangle^{d, e}(\mathrm{pA})$ & $\mathrm{CV}_{1}$ & $\mathrm{CV}_{2}$ & $\log _{10}\left[\alpha_{p}\right]$ \\
\hline \multirow[t]{2}{*}{ \#1 } & $2 / 1$ & 468 & $1(1)$ & \multirow[t]{2}{*}{$7 \pm 1$} & $0.61 \pm 0.07$ & \multirow[t]{2}{*}{$149 \pm 7$} & \multirow[t]{2}{*}{$0.29 \pm 0.07$} & \multirow[t]{2}{*}{$0.11 \pm 0.11$} & \multirow[t]{2}{*}{$1.4 \pm 0.8$} \\
\hline & $0.5 / 2.5$ & 322 & $430(429)$ & & $0.08 \pm 0.01$ & & & & \\
\hline \multirow[t]{2}{*}{$\# 2$} & $2 / 1$ & 612 & $34(33)$ & \multirow{2}{*}{$3 \pm 0$} & $0.63 \pm 0.02$ & \multirow{2}{*}{$248 \pm 4$} & \multirow{2}{*}{$0.22 \pm 0.01$} & \multirow{2}{*}{$0.36 \pm 0.02$} & \multirow[t]{2}{*}{$1.8 \pm 0.3$} \\
\hline & $0.5 / 2.5$ & 227 & 909 (908) & & $0.07 \pm 0.004$ & & & & \\
\hline \multirow[t]{2}{*}{ \#3 } & $2 / 1$ & 533 & $13(8)$ & \multirow[t]{2}{*}{$5 \pm 0$} & $0.57 \pm 0.01$ & \multirow[t]{2}{*}{$227 \pm 5$} & \multirow{2}{*}{$0.14 \pm 0.02$} & \multirow[t]{2}{*}{$0.36 \pm 0.01$} & \multirow[t]{2}{*}{$1.8 \pm 0.3$} \\
\hline & $0.5 / 2.5$ & 246 & $731(729)$ & & $0.06 \pm 0.004$ & & & & \\
\hline \multirow[t]{4}{*}{ \#4 } & $3 / 3$ & 197 & $0(0)$ & \multirow[t]{4}{*}{$6 \pm 0.5$} & $0.67 \pm 0.03$ & \multirow[t]{4}{*}{$164 \pm 14$} & \multirow[t]{4}{*}{$0.10 \pm 0.02$} & \multirow[t]{4}{*}{$0.49 \pm 0.02$} & \multirow[t]{4}{*}{$1.6 \pm 0.3$} \\
\hline & $2 / 3$ & 351 & $10(14)$ & & $0.42 \pm 0.02$ & & & & \\
\hline & $1 / 3$ & 115 & $93(70)$ & & $0.17 \pm 0.02$ & & & & \\
\hline & $0.3 / 3$ & 29 & $431(428)$ & & $0.01 \pm 0.002$ & & & & \\
\hline \multirow[t]{4}{*}{ \#5 } & $4 / 0.5$ & 111 & $0(0)$ & \multirow[t]{4}{*}{$7 \pm 1$} & $0.72 \pm 0.07$ & \multirow[t]{4}{*}{$129 \pm 6$} & \multirow[t]{4}{*}{$0.14 \pm 0.04$} & \multirow[t]{4}{*}{$0.37 \pm 0.03$} & \multirow[t]{4}{*}{$2 \pm 0.5$} \\
\hline & $2 / 1$ & 118 & $2(3)$ & & $0.41 \pm 0.04$ & & & & \\
\hline & $1 / 2$ & 165 & $27(30)$ & & $0.23 \pm 0.03$ & & & & \\
\hline & $0.5 / 2.5$ & 55 & $282(280)$ & & $0.03 \pm 0.003$ & & & & \\
\hline
\end{tabular}

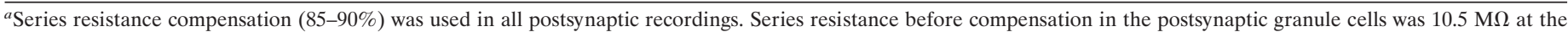

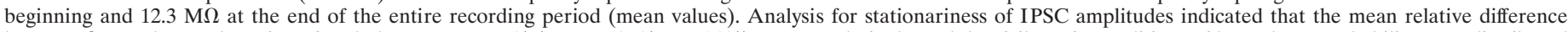

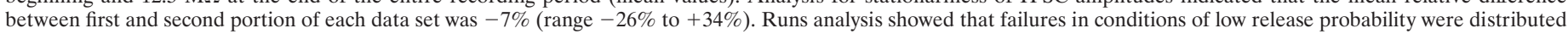
randomly in all cells except pair \#5 $(p>0.05)$.

${ }^{b}$ Failures represent measured values; predicted values are given in parentheses.

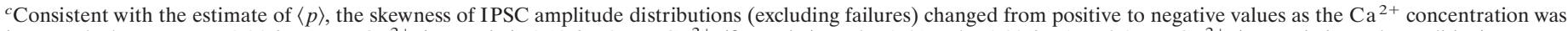
increased; skewness was 0.84 for $1 \mathrm{mM} \mathrm{Ca}^{2+}$ (two pairs), 0.12 for $2 \mathrm{~mm} \mathrm{Ca}^{2+}$ (five pairs), and -0.56 and -0.28 for 3 and $4 \mathrm{~mm} \mathrm{Ca}^{2+}$ (one pair in each condition).

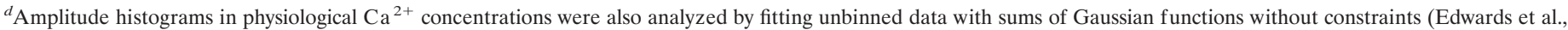

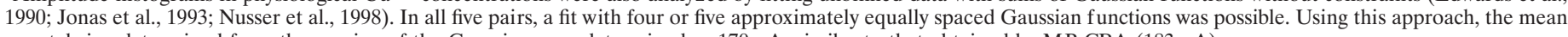
quantal size determined from the spacing of the Gaussians was determined as $170 \mathrm{pA}$, similar to that obtained by MP-CBA (183 pA).

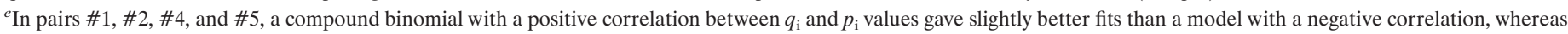

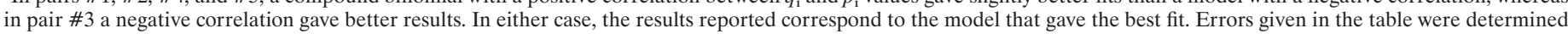

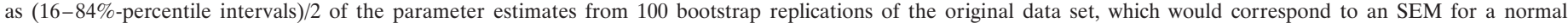
distribution.

Figure 7. Properties of PPD of IPSCs at the BC-GC synapse. $A$, IPSCs evoked by pairs of action potentials in the presynaptic $\mathrm{BC}$, separated by intervals of variable duration. Traces shown are averages of 30 unitary IPSCs and were normalized to the same amplitude for the first average IPSC (absolute values of $A_{1}$ were 1393,1180 , and $1216 \mathrm{pA}$, respectively). B, Time course of recovery from PPD. The ratio of amplitudes of the second $\left(A_{2}\right)$ and the first $\left(\mathrm{A}_{1}\right)$ unitary IPSC, both measured from their respective baselines as indicated in A, was plotted against the interpulse interval. The curve represents a fitted exponential function with a time constant of $1.97 \mathrm{sec}$. Number of pairs is indicated in parentheses above the data points. $C, \mathrm{Co}-$ efficient of variation analysis suggests a presynaptic locus of PPD. The inverse of the square of the coefficient of variation of $A_{2}$ $\left(\mathrm{CV}^{-2}\right)$ was plotted against the mean peak amplitude; data were normalized by the $\mathrm{CV}^{-2}$ and mean, respectively, of $A_{1}$. Data are from 10 pairs. Intervals between presynaptic action potentials were $100 \mathrm{msec}(\boldsymbol{\nabla}), 500$ $\operatorname{msec}(\nabla), 1 \sec (\square), 2 \sec (\square)$, and $3 \sec (\bullet)$. Curve a represents the prediction of Equation 8 of Silver et al. (1998) for a pure change in release probability $p$ superimposed on the data points (number of release sites $=5$, release probability $=0.53, \mathrm{CV}_{1}=0.18$, $\mathrm{CV}_{2}=0.34$; no variation in $\left.\mathrm{p}\right)$. Curve $e$ rep-
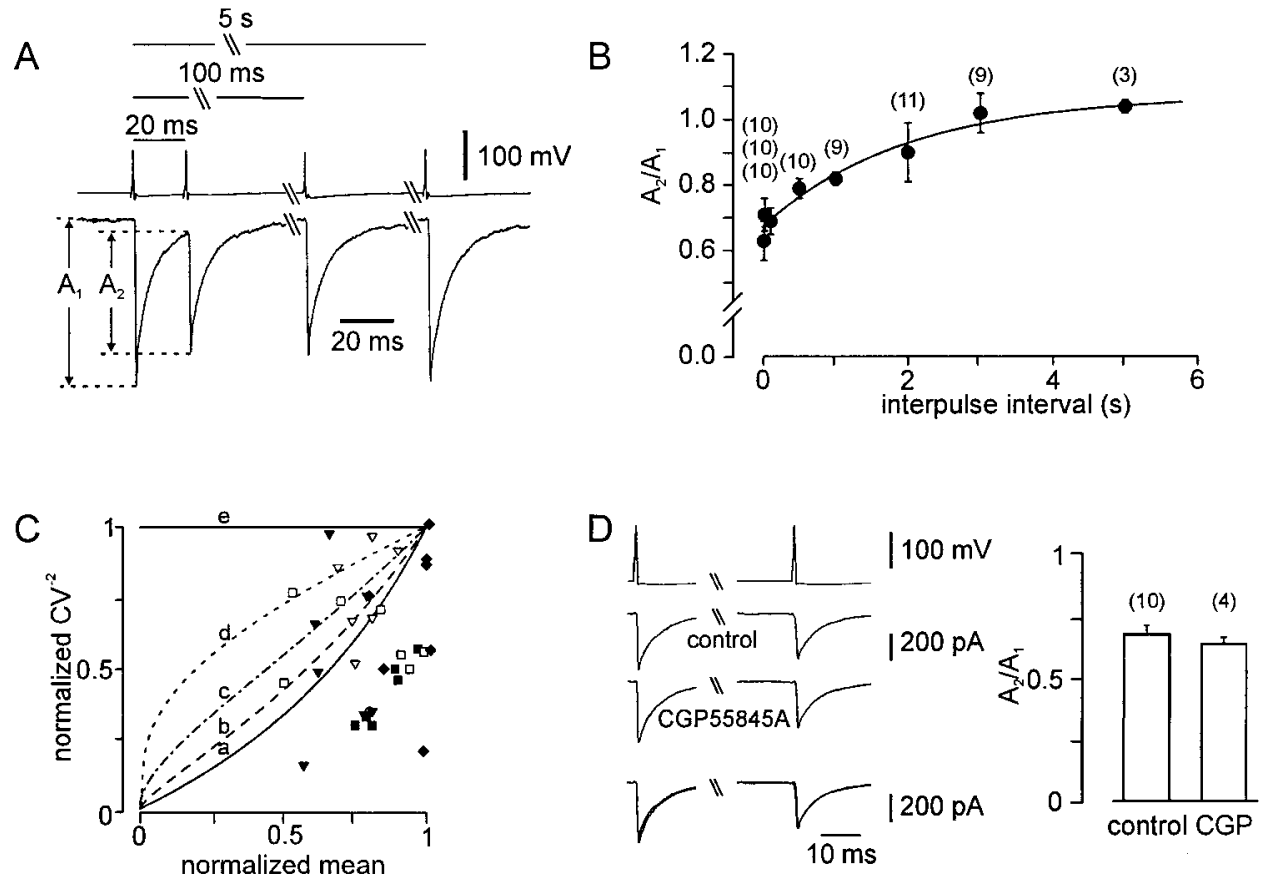

resents the prediction of a pure change in quantal size $q$, and curves $b-d$ show predictions for mixed changes $(75,50$, and $25 \%$ contribution of changes in $p$, with $p=x^{\mathrm{a}}$ and $q=x^{1-\mathrm{a}}$, where $a$ is the fractional contribution of the change in $p$ and $x$ is the normalized mean). $D$, PPD appears to be independent of presynaptic GABA receptor activation. Left, Average IPSCs in control conditions (top) and in the presence of $5 \mu \mathrm{M}$ CGP55845A in the bath solution (center) are depicted, together with a superposition of both traces (bottom). Right, Summary bar graph of mean $A_{2} / \mathrm{A}_{1}$ in control conditions and in the presence of CGP55845A. Extracellular $\mathrm{Ca}^{2+}$ and $\mathrm{Mg}^{2+}$ concentrations were 2 and $1 \mathrm{~mm}$, respectively. Interpulse interval, 100 msec. Failures included in all averages. Number of pairs indicated in parentheses above the bars.

Among the alternatives tested, the model with the activitydependent reduction in release probability would be most consistent with the experimental observations. Unlike the other models, it predicts the biexponential time course of multiple-pulse depres- sion (Fig. 10B) very closely. Furthermore, the model predicts the approximate extent of PPD and the independence of PPD on release probability (Fig. 10, legend). If this model is used to fit the depression data in Figure 9, $C-E$ and $H$, with release probabilities 

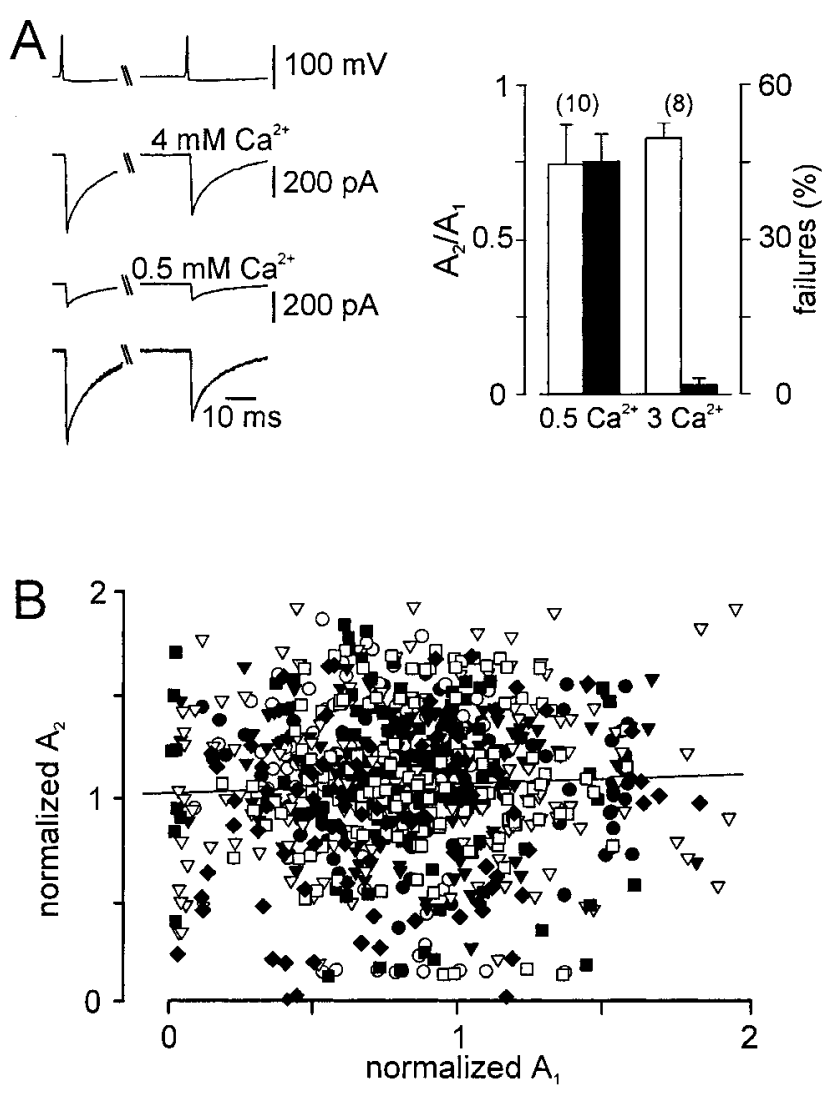

Figure 8. PPD at the BC-GC synapse appears to be independent of release probability and previous exocytosis. $A$, PPD is independent of extracellular $\mathrm{Ca}^{2+}$ concentration. Left, Average IPSCs in $4 \mathrm{mM} \mathrm{Ca}^{2+} / 0.5$ $\mathrm{mM} \mathrm{Mg}^{2+}$ (top) or $0.5 \mathrm{mM} \mathrm{Ca}^{2+} / 4 \mathrm{mM} \mathrm{Mg}^{2+}$ (center) are depicted (failures included), together with a superposition of both traces after normalization to give the same peak amplitude for the first average IPSC (bottom). Right, Mean $A_{2} / A_{1}$ (open bars) and percentage of failures (filled bars) for 0.5 and $3 \mathrm{~mm} \mathrm{Ca}{ }^{2+} / 3 \mathrm{~mm} \mathrm{Mg}^{2+}$. Interpulse interval, $100 \mathrm{msec}$. Number of pairs indicated in parentheses on top. $B$, PPD appears to be independent of previous release. Plot of $A_{2}$ against $A_{1}$ for individual events is shown. Amplitudes were normalized to the mean $A_{1}$ in the recorded ensemble. Line represents the results of linear regression. No significant correlation between IPSC peak amplitudes was apparent $(p>0.05)$; interpulse inter$\mathrm{val}, 100 \mathrm{msec}$. Data were from 10 pairs; different pairs are represented by different symbols.

constrained to the mean values obtained by MP-CBA (Fig. 6D, Table 2), we estimate that the capacity of the releasable pool is 51 vesicles per release site at the $\mathrm{BC}-\mathrm{GC}$ synapse (see Discussion and continuous curves in Fig. 9 for quantitative predictions).

\section{DISCUSSION}

Although synapses with a single release site will be required to assess certain mechanistic aspects of synaptic transmission (Auger et al., 1998), multi-site synapses appear to be much more abundant in the mammalian CNS (Buhl et al., 1994; Tamás et al., 1997). The BC-GC synapse in the hippocampus is a particularly favorable model of an inhibitory multi-site synapse. Relatively high connectivity and excellent recording conditions (voltage clamp, signal-tonoise ratio) allow a rigorous assessment of basic properties of quantal synaptic transmission in the paired recording configuration. The virtual absence of any form of enhancement of synaptic strength at this synapse offers the additional advantage that the mechanisms of depression can be examined in isolation. Together with previous analysis of excitatory transmission at the GC-BC synapse (Geiger et al., 1997, 1999), the present results also advance our understanding of synaptic signaling in recurrent inhibitory microcircuits in the dentate gyrus.

\section{Quantal size at the BC-GC synapse}

The estimated quantal conductance at the $\mathrm{BC}-\mathrm{GC}$ synapse in high intracellular $\mathrm{Cl}^{-}$concentration was $1.7 \mathrm{nS}$ (Fig. 4D). If the singlechannel conductance of postsynaptic $\mathrm{GABA}_{\mathrm{A}}$ receptors is assumed to be $30 \mathrm{pS}$ at $34^{\circ} \mathrm{C}$ (Brickley et al., 1999; Perrais and Ropert, 1999), this would imply the opening of $57 \mathrm{GABA}_{\mathrm{A}} \mathrm{R}$ channels at the peak of a quantal IPSC. If the current flow through $\mathrm{GABA}_{\mathrm{A}} \mathrm{Rs}$ expressed in GCs follows the Goldman-Hodgkin-Katz equation, the quantal conductance in physiological $\mathrm{Cl}^{-}$concentrations would be predicted to be $\sim 0.5 \mathrm{nS}$ [chord conductance at $+10 \mathrm{mV}$ calculated using the Goldman-Hodgkin-Katz current equation for $6 \mathrm{~mm}$ intracellular $\mathrm{Cl}^{-}$(Hille, 1992; also see Bormann et al., 1987)]. Considering that the resting input conductance of a GC is approximately $2 \mathrm{nS}$ (Spruston and Johnston, 1992), this suggests that a quantal event has considerable shunting effects under physiological conditions.

Our values of the quantal conductance at the BC-GC synapse are larger than previous estimates for inhibitory synapses on hippocampal granule cells [0.2-0.4 nS, high intracellular $\mathrm{Cl}^{-}$(Edwards et al., 1990); $0.4 \mathrm{nS}$, low intracellular $\mathrm{Cl}^{-}$(Nusser et al., 1998)]. Differences in recording temperature $\left(34^{\circ} \mathrm{C}\right.$ in this paper vs $21-23^{\circ} \mathrm{C}$ in the other studies) certainly contribute to this apparent difference but are unlikely to explain it entirely. It is possible that different presynaptic interneuron subtypes were activated in the different studies. Presynaptic interneurons in the present experiments were selected according to fast spiking during sustained current injection, which will bias the sample toward parvalbuminpositive basket cells (Freund and Buzsáki, 1996; Cauli et al., 1997; Lübke et al., 1998). In contrast, interneurons activated in the other studies by minimal extracellular axonal stimulation may also include CCK/VIP-positive basket cells or HICAP cells with axons coaligned with the commissural-associational pathway (Freund and Buzsáki, 1996; Cauli et al., 1997; Lübke et al., 1998).

\section{Release probability and $\mathrm{Ca}^{2+}$ dependence}

The mean release probability at the $\mathrm{BC}-\mathrm{GC}$ synapse in physiological divalent concentrations, determined by compound binomial analysis, was $\sim 0.4-0.6$ (Fig. 6). The dependence of release probability on extracellular $\mathrm{Ca}^{2+}$ concentration at the $\mathrm{BC}-\mathrm{GC}$ synapse is consistent with the cooperative binding of $>2 \mathrm{Ca}^{2+}$ ions to the putative $\mathrm{Ca}^{2+}$ sensor, probably synaptotagmin (Südhof, 1995). The apparent Hill coefficient (2.4) is lower, however, than that at the frog neuromuscular junction $(\sim 3.8)$ (Dodge and Rahamimoff, 1967) or at glutamatergic autapses (3.3) (Reid et al., 1998). This may reflect a difference between inhibitory or excitatory terminals (e.g., in the synaptotagmin isoforms present). Alternatively, the lower Hill coefficient of inhibitory synapses may be attributable to intersite differences in the $\mathrm{EC}_{50}$ values among terminals of the same connection, which will result in reduction of the apparent Hill coefficient.

The maximal release probability that is approached at high $\mathrm{Ca}^{2+}$ concentrations (extrapolated value $\sim 0.8$ ) (Fig. $6 D$ ) indicates a high efficacy of coupling of $\mathrm{Ca}^{2+}$ inflow to exocytosis at the $\mathrm{BC}-\mathrm{GC}$ synapse. Furthermore, the high maximal release probability suggests that axonal conduction of a single spike is reliable, despite the extensive arborization of the BC axon (Freund and Buzsáki, 1996). The proportion of conduction failures in physiological divalent concentrations is probably much less than 0.2 (1 maximal release probability), because an increase in $\mathrm{Ca}^{2+}$ concentration is likely to reduce the safety factor of transmission, for example, caused by screening of surface charges (Frankenhaeuser and Hodgkin, 1957).

\section{The BC-GC synapse is a multi-site connection}

The present results indicate that synaptic events at the $\mathrm{BC}-\mathrm{GC}$ synapse are generated at three to seven functional release sites (Fig. 6, Table 2). This value appears to be in approximate agreement with the estimated number of anatomical release sites at 
Figure 9. Depression of IPSCs at the BC-GC synapse during multiple-pulse stimulation. $A$, Unitary IPSCs during a $20 \mathrm{~Hz}$ train of 1000 action the train was $0.25 \mathrm{~Hz}$. Presynaptic action potentials (top) were truncated. B, Unitary IPSCs at an expanded time scale from the same pair as shown in $A$ in control conditions (top), at the end of the 20 $\mathrm{Hz}$ train (center), and after recovery (bottom). C, Onset of depression during a $20 \mathrm{~Hz}$ train. Each data point represents the mean IPSC peak amplitude in 23 pairs, normalized to the mean peak amplitude at $0.25 \mathrm{~Hz}$ before the train. $D$, Plot of mean unitary IPSC peak amplitudes (action potentials 851-900, failures included) against stimulation frequency, normalized to the control value (at 0.25 $\mathrm{Hz}$ ). Number of pairs indicated in parentheses above the data points. $E$, Recovery from depression induced by a $20 \mathrm{~Hz}$ train. Each data point represents the mean peak amplitude from one (first point) or three (all following points) consecutive IPSCs in 23 pairs, normalized to the mean peak amplitude at $0.25 \mathrm{~Hz}$ after complete recovery from depression (which, on average, was 1.05-fold larger than that before the train, indicating a slight post-tetanic potentiation). $F$, Coefficient of variation analysis of short-term depression. The inverse of the square of the CV of the peak amplitude of plotted against the mean peak amplitude for different frequencies; data were normalized by the $\mathrm{CV}^{-2}$ and mean, respectively, of IPSCs evoked at $0.25 \mathrm{~Hz}$. Stimulation frequency was $1 \mathrm{~Hz}(\bullet), 2 \mathrm{~Hz}$ $(\bigcirc), 10 \mathrm{~Hz}(\boldsymbol{\nabla}), 20 \mathrm{~Hz}(\nabla), 40 \mathrm{~Hz}(\boldsymbol{\square})$, and $50 \mathrm{~Hz}$ ( $\square)$. Curve a represents the prediction of Equation 8 of Silver et al. (1998) for a pure change in $p$ superimposed on the data points (with same parameters as in Fig. 7). Curve e represents the prediction of a pure change in $q$, and curves $b-d$ show predictions for mixed changes $(75,50$, and $25 \%$ contribution of changes in $p$ ). $G$, Onset of depresCGP55845A. Each data point represents the mean peak amplitude in seven pairs, normalized to the mean peak amplitude at $0.25 \mathrm{~Hz}$ before the train. $H$, The slow component of depression appears to be dependent on release probability. Onset of de$\mathrm{mM} \mathrm{Mg}^{2+}\left(9\right.$ pairs, $\bigcirc$ ) and $2 \mathrm{mM} \mathrm{Ca}^{2+} / 1 \mathrm{mM} \mathrm{Mg}^{2+}$ (๑). Each data point represents the mean peak amplitude, normalized to the mean peak amplitudes at $0.25 \mathrm{~Hz}$ before the train. I, Correlation of peak amplitudes of consecutive IPSCs in the late portion of $20 \mathrm{~Hz}$ trains (last 500 action potentials) in $2 \mathrm{mM} \mathrm{Ca}^{2+} / 1 \mathrm{mM} \mathrm{Mg}^{2+}$. Peak amplitudes $A_{\mathrm{n}+1}$ of IPSCs (or failures) were plotted against the amplitudes $A_{\mathrm{n}}$ of the directly preceding IPSCs (or failures), both normalized to the mean amplitude of the data set. Eleven of 11500 points are located outside the plot range. Line represents the results of linear regression. A slight but significant negative correlation between IPSC peak amplitudes was apparent (slope $-0.054 ; p<0.001$ ). Extracellular $\mathrm{Ca}^{2+}$ and $\mathrm{Mg}^{2+}$ concentrations were 2 and 1 $E, G$, and $H$ indicates the time of change in frequency. SEMs in $C, G$, and $H$ were not shown for clarity. Continuous curves in $C-E$ and $H$ represent the predictions of a two-pool model with activitydependent reduction in release probability fitted to the data points (Fig. 10). potentials; stimulation frequency before and after unitary IPSCs (action potentials 851-900) was sion during a $20 \mathrm{~Hz}$ train in the presence of $5 \mu \mathrm{M}$ pression during $20 \mathrm{~Hz}$ trains in $0.5 \mathrm{mM} \mathrm{Ca}^{2+} / 2.5$ $\mathrm{mm}$, respectively, in all cases except $H$. Time 0 in $C$,
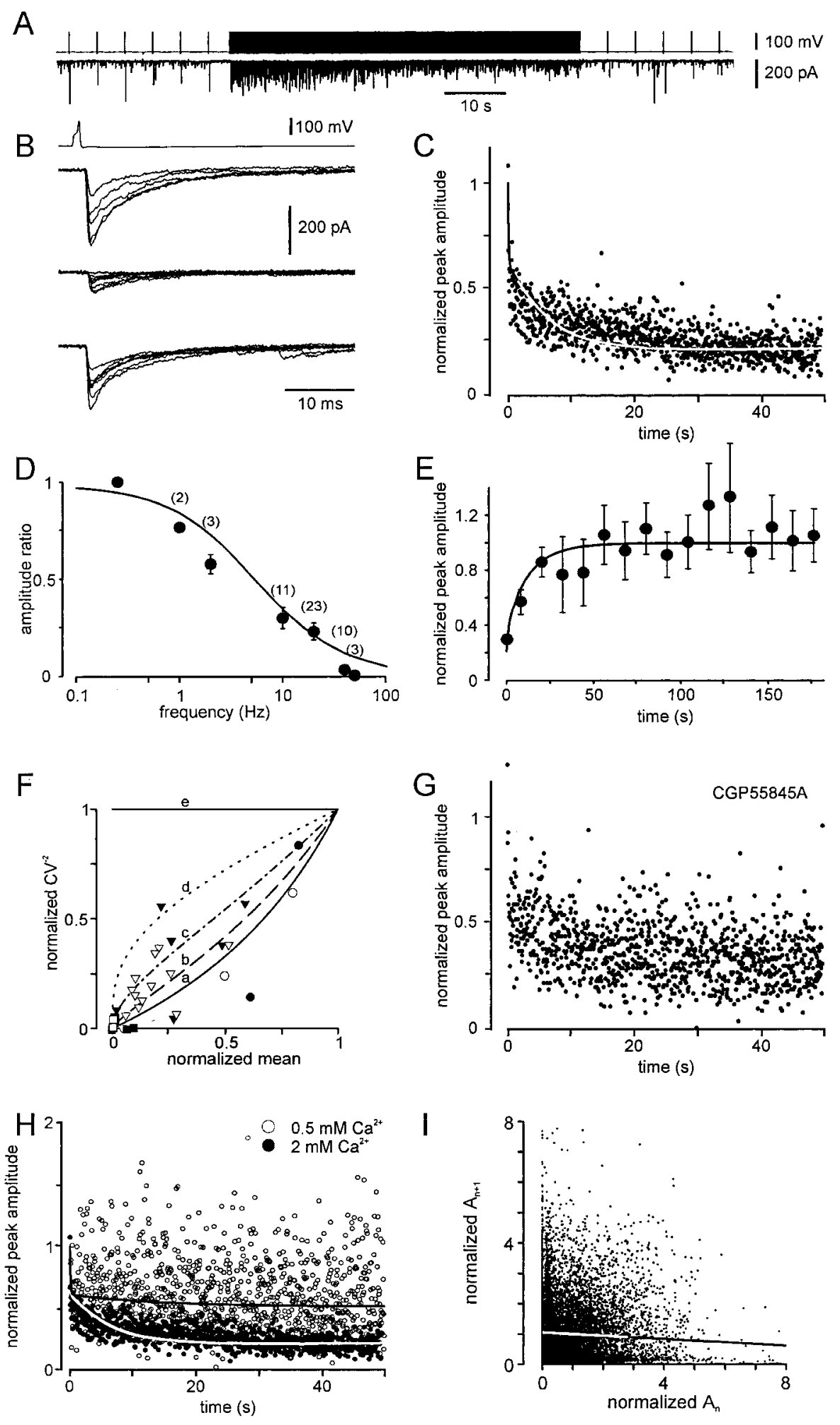

inhibitory synapses in the hippocampus determined by electron microscopic analysis [10-12 inhibitory contacts between basket cells and pyramidal neurons in the CA1 subfield; eight inhibitory contacts between axo-axonic cells and GCs (Buhl et al., 1994); two to six inhibitory contacts between perisomatic inhibitory cells and pyramidal neurons in the CA3 region (Miles et al., 1996); two to four inhibitory contacts between BCs and GCs (Geiger et al., 1997; J. Lübke, personal communication). It remains to be determined whether BC-GC synaptic contacts comprise a single release site or multiple release sites, as reported previously for dendrite-targeting interneurons in the neocortex (Tamás et al., 1997).

\section{The locus of PPD is upstream of the exocytotic step}

Synaptic depression has been attributed to desensitization of postsynaptic receptors (Jones and Westbrook, 1995, 1996), negative feedback by presynaptic metabotropic receptors (Deisz and Prince, 1989; Lambert and Wilson, 1994), synaptic refractoriness (Stevens and Wang, 1995), or depletion of the releasable pool of synaptic vesicles (Debanne et al., 1996; Dobrunz and Stevens, 1997). None of these factors, however, appears to be primarily responsible for PPD of unitary IPSCs at the BC-GC synapse. 
$\mathrm{A} a$
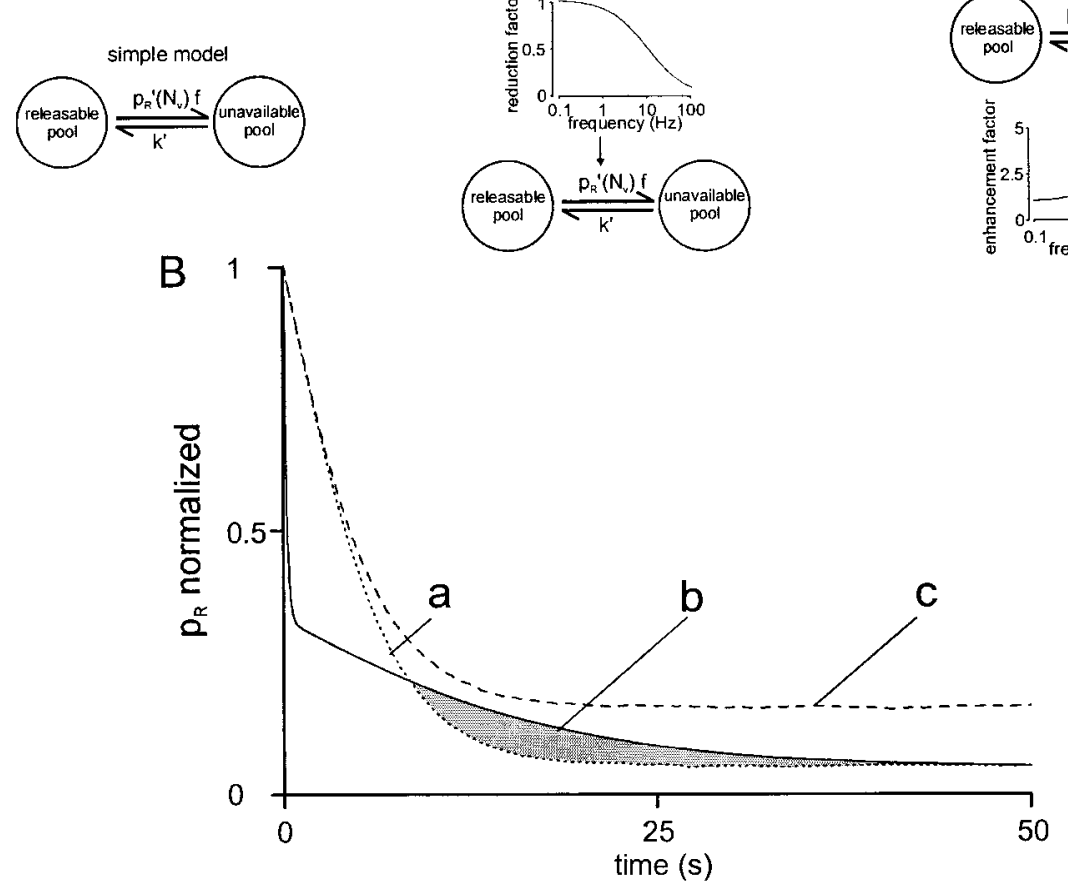

b

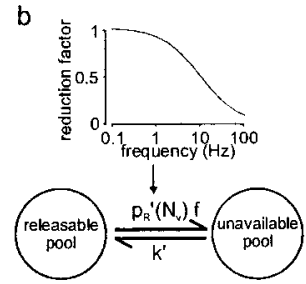

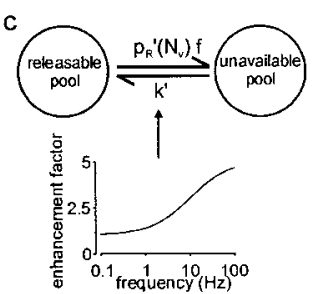

Figure 10. Activity-dependent gating of release may prevent depletion of the releasable pool of synaptic vesicles. $A$, Schematic illustration of different vesicular pool models. Univesicular release constraint. The capacity of the releasable pool $\left(N_{\mathrm{v} 0}\right)$ was assumed as 50 , the initial release probability $\left(p_{\mathrm{R}}\right.$ at time 0$)$ as 0.5 , and the refilling rate as $k=0.01 \mathrm{sec}^{-1} . a$, Two-pool model with constant rates. $b$, Two-pool model with activity-dependent reduction in release probability (Betz, 1970). Activity-dependent reduction of $p_{\mathrm{R}}$ was defined by $a_{\max }=1, \alpha=0.2$, and $\beta=$ $2 \mathrm{sec}^{-1}$, yielding a half-maximal activating frequency at $10 \mathrm{~Hz}$ and a maximal time constant of $0.5 \mathrm{sec}$. $c$, Two-pool model with activity-dependent refilling of the releasable pool (Kusano and Landau, 1975). Activity-dependent increase of $k$ was defined by $a_{\max }=4, \alpha=0.2$, and $\beta=$ $2 \mathrm{sec}^{-1}$. The frequency dependence of the reduction and enhancement factor, respectively, in steady-state conditions is illustrated adjacent to the affected rate. $B$, Mean release probability $p_{\mathrm{R}}$ during $20 \mathrm{~Hz}$ trains, normalized to the initial value. Dotted curve indicates model $a$; continuous curve, model $b$; dashed curve, model $c$. The shaded area indicates the gain of IPSC amplitude in the late phase of the train, generated by redistribution of release events from the early to the late phase. Note that the prediction of model $b$ is consistent with the time course of onset of

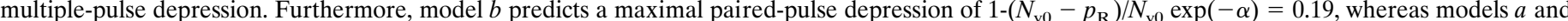

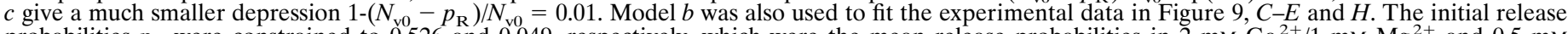

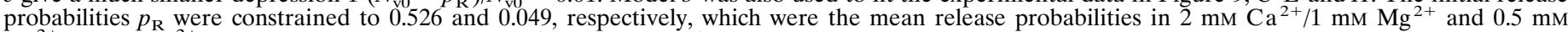

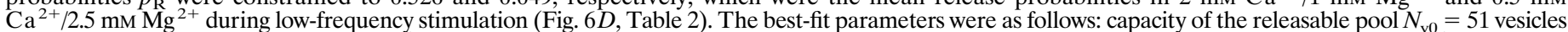

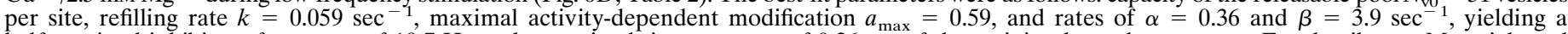

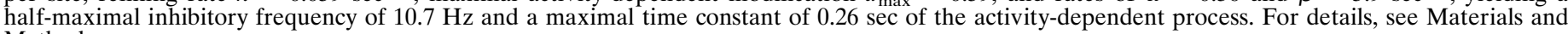
Methods.

Desensitization of postsynaptic $\mathrm{GABA}_{\mathrm{A}}$ receptors is not the major factor underlying PPD, because $C V$ analysis suggested that the primary locus of PPD is presynaptic. Presynaptic receptors do not appear to be involved, because PPD at the BC-GC synapse was unaffected by the high-affinity $\mathrm{GABA}_{\mathrm{B}}$ receptor antagonist CGP55845A (Kaupmann et al., 1997). Synaptic refractoriness is not expected to contribute to PPD, because recovery from refractoriness is thought to be complete within $\sim 10 \mathrm{msec}$ (Stevens and Wang, 1995). Finally, pool depletion was unlikely, because the extent of PPD was independent of extracellular $\mathrm{Ca}^{2+}$ concentration, and a negative correlation between the amplitudes of first and second IPSCs was not observed (Fig. $8)$. The independence of PPD on extracellular $\mathrm{Ca}^{2+}$ concentration and previous release further argues against both desensitization of postsynaptic $\mathrm{GABA}_{\mathrm{A}}$ receptors and activation of presynaptic $\mathrm{GABA}_{\mathrm{B}}$ receptors. More generally, this independence argues against the involvement of any type of presynaptic receptor activated by modulators coreleased with GABA.

Although desensitization does not underlie PPD, it is possible that it is involved in the generation of the slow component of IPSC decay ( 9 msec in this study), which may reflect transitions of postsynaptic $\mathrm{GABA}_{\mathrm{A}}$ receptors from desensitized to open states (Jones and Westbrook, 1995, 1996). If this were the case, postsynaptic $\mathrm{GABA}_{\mathrm{A}}$ receptors may have largely recovered from desensitization at times when PPD is still substantial (e.g., at $100 \mathrm{msec}$ ).

On the basis of this evidence, we conclude that PPD at the $\mathrm{BC}-\mathrm{GC}$ synapse is generated by a mechanism located upstream of the exocytotic step. Candidate mechanisms include (1) increased probability of axonal conduction failures after the first spike (Lüscher and Shiner, 1990), (2) changes in duration of the presynaptic spike resulting in reduced $\mathrm{Ca}^{2+}$ inflow (Geiger and Jonas, 1999), (3) inactivation of presynaptic $\mathrm{Ca}^{2+}$ channels (Patil et al., 1998), (4) $\mathrm{Ca}^{2+}$ depletion in the extracellular space (Borst and Sakmann, 1999), and (5) reduction of release probability after the first spike (Betz, 1970; Faber et al., 1998), which may reflect desensitization of the $\mathrm{Ca}^{2+}$ sensor that triggers release or direct voltage-dependent inactivation of the release machinery. Evidence for releaseindependent forms of PPD has also accumulated recently for other synapses (Dobrunz et al., 1997; Bellingham and Walmsley, 1999; Geiger et al., 1999; Thomson and Bannister, 1999).

\section{The slow component of multiple-pulse depression: depletion of the releasable pool?}

During a train of presynaptic action potentials, unitary IPSC peak amplitudes at the BC-GC synapse decline biexponentially (Fig. $9 C$ ). The fast component of depression may correspond to PPD, whereas the slow component appears to be distinct. Desensitization of postsynaptic $\mathrm{GABA}_{\mathrm{A}}$ receptors is unlikely to be the main factor underlying the slow component of depression, because $\mathrm{CV}$ analysis suggested a mainly presynaptic origin. Presynaptic autoreceptors provide a small contribution to slow depression, as indicated by the slight reduction of multiple-pulse depression by CGP55845A (Jensen et al., 1999; this paper); however, depletion of the releasable pool of synaptic vesicles (Liley and North, 1953) is the most likely mechanism for this slow depression. This is supported by the dependence of slow depression on release probability (Fig. 9H) and the negative correlation between amplitudes of consecutive IPSCs (Fig. 9I) (Matveev and Wang, 2000).

Assuming that the two phases of multiple-pulse depression are shaped by a fast depression mechanism upstream of the release machinery and a slow depression mechanism corresponding to depletion of the readily releasable pool, we estimate that the capacity of the releasable pool at the BC-GC synapse is $\sim 50$ per release site. It is not clear whether this pool corresponds to the "readily releasable pool" (Stevens and Tsujimoto, 1995) or comprises both a readily releasable and a "reserve" pool (Liu and Tsien, 1995b). If our pool corresponds to the readily releasable pool, it would be larger than that at excitatory synapses in cultured neurons $(\sim 20)$ (Stevens and Tsujimoto, 1995). 


\section{Activity-dependent gating of release may stabilize inhibition}

The possible coexistence of a fast depression generated by a gating mechanism upstream of the exocytotic event and a slow depression caused by depletion of the releasable pool raises the question of how these two forms of depression interact during high-frequency activity. One possibility is that activity-dependent reduction in release probability, somewhat counter-intuitively, protects against depletion of the releasable pool of synaptic vesicles, thus conferring stability of transmission (Betz, 1970; Brenowitz et al., 1998). As shown in Figure $10 \mathrm{~B}$, the predicted IPSC amplitudes during a high-frequency train for the model with constant rates and the model with activity-dependent reduction of release probability show crossover, implying that vesicles saved in the early phase can be released in the late phase of the train (shaded area). Because GABAergic interneurons in the hippocampus in vivo generate action potentials over a wide range of frequencies with mean values of 10-20 Hz (Penttonen et al., 1998; Csicsvari et al., 1999), redistribution of synaptic efficacy within a train may contribute to the stability of transmission at GABAergic synapses in the hippocampal network of the behaving rat.

\section{REFERENCES}

Auger C, Kondo S, Marty A (1998) Multivesicular release at single functional synaptic sites in cerebellar stellate and basket cells. J Neurosci 18:4532-4547.

Barbour B, Häusser M (1997) Intersynaptic diff usion of neurotransmitter. Trends Neurosci 20:377-384.

Barrett EF, Stevens CF (1972) The kinetics of transmitter release at the frog neuromuscular junction. J Physiol (Lond) 227:691-708.

Bellingham MC, Walmsley B (1999) A novel presynaptic inhibitory mechanism underlies paired pulse depression at a fast central synapse. Neuron 23:159-170.

Betz WJ (1970) Depression of transmitter release at the neuromuscular junction of the frog. J Physiol (Lond) 206:629-644.

Bormann J, Hamill OP, Sakmann B (1987) Mechanism of anion permeation through channels gated by glycine and $\gamma$-aminobutyric acid in mouse cultured spinal neurones. J Physiol (Lond) 385:243-286.

Borst JGG, Sakmann B (1999) Depletion of calcium in the synaptic cleft of a calyx-type synapse in the rat brainstem. J Physiol (Lond) 521:123-133.

Brenowitz S, David J, Trussell L (1998) Enhancement of synaptic efficacy by presynaptic GABA $_{\mathrm{B}}$ receptors. Neuron 20:135-141.

Brickley SG, Cull-Candy SG, Farrant M (1999) Single-channel properties of synaptic and extrasynaptic $\mathrm{GABA}_{\mathrm{A}}$ receptors suggest differential targeting of receptor subtypes. J Neurosci 19:2960-2973.

Buhl EH, Halasy K, Somogyi P (1994) Diverse sources of hippocampal unitary inhibitory postsynaptic potentials and the number of synaptic release sites. Nature 368:823-828.

Caceci MS, Cacheris WP (1984) Fitting curves to data. Byte 8:340-362.

Cauli B, Audinat E, Lambolez B, Angulo MC, Ropert N, Tsuzuki K, Hestrin S, Rossier J (1997) Molecular and physiological diversity of cortical nonpyramidal cells. J Neurosci 17:3894-3906.

Cobb SR, Buhl EH, Halasy K, Paulsen O, Somogyi P (1995) Synchronization of neuronal activity in hippocampus by individual GABAergic interneurons. Nature 378:75-78.

Csicsvari J, Hirase H, Czurkó A, Mamiya A, Buzsáki G (1999) Oscillatory coupling of hippocampal pyramidal cells and interneurons in the behaving rat. J Neurosci 19:274-287.

Davison AC, Hinkley DV, Schechtman E (1986) Efficient bootstrap simulation. Biometrika 73:555-566.

Debanne D, Guérineau NC, Gähwiler BH, Thompson SM (1996) Pairedpulse facilitation and depression at unitary synapses in rat hippocampus: quantal fluctuation affects subsequent release. J Physiol (Lond) 491:163-176.

Deisz RA, Prince DA (1989) Frequency-dependent depression of inhibition in guinea-pig neocortex in vitro by $\mathrm{GABA}_{\mathrm{B}}$ receptor feed-back on GABA release. J Physiol (Lond) 412:513-541.

Diamond JS, Jahr CE (1995) Asynchronous release of synaptic vesicles determines the time course of the AMPA receptor-mediated EPSC. Neuron 15:1097-1107.

Dittman JS, Regehr WG (1998) Calcium dependence and recovery kinetics of presynaptic depression at the climbing fiber to Purkinje cell synapse. J Neurosci 18:6147-6162.

Dobrunz LE, Stevens CF (1997) Heterogeneity of release probability, facilitation, and depletion at central synapses. Neuron 18:995-1008.

Dobrunz LE, Huang EP, Stevens CF (1997) Very short-term plasticity in hippocampal synapses. Proc Natl Acad Sci USA 94:14843-14847.

Dodge Jr FA, Rahamimoff R (1967) Co-operative action of calcium ions in transmitter release at the neuromuscular junction. J Physiol (Lond) 193:419-432.
Edwards FA, Konnerth A, Sakmann B, Takahashi T (1989) A thin slice preparation for patch clamp recordings from neurones of the mammalian central nervous system. Pflügers Arch 414:600-612.

Edwards FA, Konnerth A, Sakmann B (1990) Quantal analysis of inhibitory synaptic transmission in the dentate gyrus of rat hippocampal slices: a patch-clamp study. J Physiol (Lond) 430:213-249.

Efron B, Tibshirani RJ (1998) An introduction to the bootstrap. London: Chapman \& Hall/CRC.

Faber DS, Waldeck R, Pereda A (1998) Synaptic depression at an identified central synapse: evidence for different constraints on evoked and spontaneous quanta. In: Central synapses: quantal mechanisms and plasticity (Faber DS, Korn H, Redman SJ, Thompson SM, Altman JS, eds), pp 158-168. Strasbourg: HFSP.

Frankenhaeuser B, Hodgkin AL (1957) The action of calcium on the electrical properties of squid axons. J Physiol (Lond) 137:218-244.

Frerking M, Borges S, Wilson M (1995) Variation in GABA mini amplitude is the consequence of variation in transmitter concentration. Neuron 15:885-895.

Freund TF, Buzsáki G (1996) Interneurons of the hippocampus. Hippocampus 6:347-470.

Galarreta M, Hestrin S (1998) Frequency-dependent synaptic depression and the balance of excitation and inhibition in the neocortex. Nat Neurosci 1:587-594.

Geiger JRP, Jonas P (1999) Activity-dependent broadening of presynaptic action potentials in hippocampal mossy fiber boutons. Soc Neurosci Abstr 25:803.

Geiger JRP, Lübke J, Roth A, Frotscher M, Jonas P (1997) Submillisecond AMPA receptor-mediated signaling at a principal neuroninterneuron synapse. Neuron 18:1009-1023.

Geiger JRP, Roth A, Taskin B, Jonas P (1999) Glutamate-mediated synaptic excitation of cortical interneurons. In: Ionotropic glutamate receptors in the CNS, handbook of experimental pharmacology 141 (Jonas P, Monyer H eds), pp 363-398. Berlin: Springer.

Han Z-S, Buhl EH, Lörinczi Z, Somogyi P (1993) A high degree of spatial selectivity in the axonal and dendritic domains of physiologically identified local-circuit neurons in the dentate gyrus of the rat hippocampus. Eur J Neurosci 5:395-410.

Hille B (1992) Ionic channels of excitable membranes. Sunderland, MA: Sinauer.

Isaacson JS, Walmsley B (1995) Counting quanta: direct measurements of transmitter release at a central synapse. Neuron 15:875-884.

Jack JJB, Larkman AU, Major G, Stratford KJ (1994) Quantal analysis of the synaptic excitation of CA1 hippocampal pyramidal cells. In: Molecular and cellular mechanisms of neurotransmitter release (Stjärne L, Greengard P, Grillner SE, Hökfelt TGM, Ottoson DR, eds), pp 275-299. New York: Raven.

Jensen K, Lambert JDC, Jensen MS (1999) Activity-dependent depression of GABAergic IPSCs in cultured hippocampal neurons. J Neurophysiol 82:42-49.

Jonas P, Major G, Sakmann B (1993) Quantal components of unitary EPSCs at the mossy fibre synapse on CA3 pyramidal cells of rat hippocampus. J Physiol (Lond) 472:615-663.

Jones MV, Westbrook GL (1995) Desensitized states prolong $\mathrm{GABA}_{\mathrm{A}}$ channel responses to brief agonist pulses. Neuron 15:181-191.

Jones MV, Westbrook GL (1996) The impact of receptor desensitization on fast synaptic transmission. Trends Neurosci 19:96-101.

Katz B (1969) The release of neural transmitter substances. Liverpool: Liverpool UP.

Kaupmann K, Huggel K, Heid J, Flor PJ, Bischoff S, Mickel SJ, McMaster G, Angst C, Bittiger H, Froestl W, Bettler B (1997) Expression cloning of $\mathrm{GABA}_{\mathrm{B}}$ receptors uncovers similarity to metabotropic glutamate receptors. Nature 386:239-246.

Koh D-S, Geiger JRP, Jonas P, Sakmann B (1995) $\mathrm{Ca}^{2+}$-permeable AMPA and NMDA receptor channels in basket cells of rat hippocampal dentate gyrus. J Physiol (Lond) 485:383-402.

Korn H, Mallet A, Triller A, Faber DS (1982) Transmission at a central inhibitory synapse. II. Quantal description of release, with a physical correlate for binomial $n$. J Neurophysiol 48:679-707.

Kusano K, Landau EM (1975) Depression and recovery of transmission at the squid giant synapse. J Physiol (Lond) 245:13-32.

Lambert NA, Wilson WA (1994) Temporally distinct mechanisms of usedependent depression at inhibitory synapses in the rat hippocampus in vitro. J Neurophysiol 72:121-130.

Liley AW, North KAK (1953) An electrical investigation of effects of repetitive stimulation on mammalian neuromuscular junction. J Neurophysiol 16:509-527.

Liu G, Tsien RW (1995a) Properties of synaptic transmission at single hippocampal synaptic boutons. Nature 375:404-408.

Liu G, Tsien RW (1995b) Synaptic transmission at single visualized hippocampal boutons. Neuropharmacology 34:1407-1421.

Lübke J, Frotscher M, Spruston N (1998) Specialized electrophysiological properties of anatomically identified neurons in the hilar region of the rat fascia dentata. J Neurophysiol 79:1518-1534. 
Lüscher H-R, Shiner JS (1990) Computation of action potential propagation and presynaptic bouton activation in terminal arborizations of different geometries. Biophys J 58:1377-1388.

Malinow R, Tsien RW (1990) Presynaptic enhancement shown by wholecell recordings of long-term potentiation in hippocampal slices. Nature 346:177-180.

Martina M, Schultz JH, Ehmke H, Monyer H, Jonas P (1998) Functional and molecular differences between voltage-gated $\mathrm{K}^{+}$channels of fastspiking interneurons and pyramidal neurons of rat hippocampus. J Neurosci 18:8111-8125.

Matveev V, Wang X-J (2000) Implications of all-or-none synaptic transmission and short-term depression beyond vesicle depletion: a computational study. J Neurosci 20:1575-1588.

Miles R, Poncer J-C (1996) Paired recordings from neurones. Curr Opin Neurobiol 6:387-394.

Miles R, Tóth K, Gulyás AI, Hájos N, Freund TF (1996) Differences between somatic and dendritic inhibition in the hippocampus. Neuron 16:815-823.

Nusser Z, Cull-Candy S, Farrant M (1997) Differences in synaptic $\mathrm{GABA}_{\mathrm{A}}$ receptor number underlie variation in GABA mini amplitude. Neuron 19:697-709.

Nusser Z, Hájos N, Somogyi P, Mody I (1998) Increased number of synaptic $\mathrm{GABA}_{\mathrm{A}}$ receptors underlies potentiation at hippocampal inhibitory synapses. Nature 395:172-177.

Patil PG, Brody DL, Yue DT (1998) Preferential closed-state inactivation of neuronal calcium channels. Neuron 20:1027-1038.

Penttonen M, Kamondi A, Acsády L, Buzsáki G (1998) Gamma frequency oscillation in the hippocampus of the rat: intracellular analysis in vivo. Eur J Neurosci 10:718-728.

Perrais D, Ropert N (1999) Effect of zolpidem on miniature IPSCs and occupancy of postsynaptic $\mathrm{GABA}_{\mathrm{A}}$ receptors in central synapses. J Neurosci 19:578-588.

Redman S (1990) Quantal analysis of synaptic potentials in neurons of the central nervous system. Physiol Rev 70:165-198.

Reid CA, Bekkers JM, Clements JD (1998) N- and P/Q-type $\mathrm{Ca}^{2+}$ channels mediate transmitter release with a similar cooperativity at rat hippocampal autapses. J Neurosci 18:2849-2855.

Silver RA, Momiyama A, Cull-Candy SG (1998) Locus of frequencydependent depression identified with multiple-probability fluctuation analysis at rat climbing fibre-Purkinje cell synapses. J Physiol (Lond) 510:881-902.
Spruston N, Johnston D (1992) Perforated patch-clamp analysis of the passive membrane properties of three classes of hippocampal neurons. J Neurophysiol 67:508-529.

Stevens CF, Tsujimoto T (1995) Estimates for the pool size of releasable quanta at a single central synapse and for the time required to refill the pool. Proc Natl Acad Sci USA 92:846-849.

Stevens CF, Wang Y (1995) Facilitation and depression at single central synapses. Neuron 14:795-802.

Stricker C, Redman S, Daley D (1994) Statistical analysis of synaptic transmission: model discrimination and confidence limits. Biophys J 67:532-547.

Stricker C, Field AC, Redman SJ (1996) Statistical analysis of amplitude fluctuations in EPSCs evoked in rat CA1 pyramidal neurones in vitro. J Physiol (Lond) 490:419-441.

Stuart GJ, Dodt H-U, Sakmann B (1993) Patch-clamp recordings from the soma and dendrites of neurons in brain slices using infrared video microscopy. Pflügers Arch 423:511-518.

Südhof TC (1995) The synaptic vesicle cycle: a cascade of protein-protein interactions. Nature 375:645-653.

Swed FS, Eisenhart C (1943) Tables for testing randomness of grouping in a sequence of alternatives. Ann Math Stat 14:66-87.

Tamás G, Buhl EH, Somogyi P (1997) Fast IPSPs elicited via multiple synaptic release sites by different types of GABAergic neurone in the cat visual cortex. J Physiol (Lond) 500:715-738.

Thomson AM, Bannister AP (1999) Release-independent depression at pyramidal inputs onto specific cell targets: dual recordings in slices of rat cortex. J Physiol (Lond) 519:57-70.

Varela JA, Song S, Turrigiano GG, Nelson SB (1999) Differential depression at excitatory and inhibitory synapses in visual cortex. J Neurosci 19:4293-4304.

Walmsley B (1995) Interpretation of 'quantal peaks' in distributions of evoked synaptic transmission at central synapses. Proc R Soc Lond B Biol Sci 261:245-250.

Weis S, Schneggenburger R, Neher E (1999) Properties of a model of $\mathrm{Ca}^{++}$-dependent vesicle pool dynamics and short term synaptic depression. Biophys J 77:2418-2429.

Wu L-G, Borst JGG (1999) The reduced release probability of releasable vesicles during recovery from short-term synaptic depression. Neuron 23:821-832. 